\title{
Application of BRFP New-Type Anchor Cable Material in High Slopes against Earthquakes
}

\author{
Honggang Wu $\mathbb{D}^{1},{ }^{1}$ Zhixin $W u^{2}$ Hao Lei $\mathbb{D}^{3},{ }^{3}$ and Tianwen $\mathrm{Lai}^{3}$ \\ ${ }^{1}$ Northwest Railway Academy Co., Ltd. of CREC, Lanzhou, Gansu 730000, China \\ ${ }^{2}$ Gansu Province Transportat Planning, Survey \& Desing Institute Co., Ltd., Lanzhou 730030, Gansu, China \\ ${ }^{3}$ School of Civil Engineering, Lanzhou Jiaotong University, Lanzhou, Gansu 730000, China \\ Correspondence should be addressed to Hao Lei; 714664532@qq.com
}

Received 11 December 2020; Revised 12 January 2021; Accepted 19 January 2021; Published 13 February 2021

Academic Editor: Chong Xu

Copyright (c) 2021 Honggang Wu et al. This is an open access article distributed under the Creative Commons Attribution License, which permits unrestricted use, distribution, and reproduction in any medium, provided the original work is properly cited.

To clarify the feasibility of BFRP (basalt fiber reinforced plastics) anchors instead of steel anchors in the seismic application of slopes under different vibration strengths, a series of shaking table tests were carried out to strengthen the slope using BFRP anchors and steel anchors, respectively. By studying the dynamic response recorded in the slope model and the observed experimental phenomena, the acceleration dynamic response and displacement spectrum dynamic response of the two slope models were analyzed. The test results show that the deformation stage of the slope reinforced by the two types of anchors is basically the same during the test, that is, elastic, plastic (potential sliding surface and plastic strengthening), and failure stages, respectively. The slope is in the elastic stage before the $0.2 \mathrm{~g}$ seismic wave, and it gradually enters the plastic stage after the $0.4 \mathrm{~g}$ seismic wave. However, the peak acceleration and displacement of the slope reinforced by steel anchors are greater than those of the slope reinforced by BFRP anchors under the same working conditions of seismic waves. In addition, we found that the acceleration response spectrum distribution curve of each measuring point in the short period has an obvious amplification effect along the elevation, and its predominant period has a forward migration phenomenon with the increase of the height of the measuring point, which also indicates that the higher frequency seismic wave has a greater impact on the top of the slope. The BFRP anchors, as a kind of flexible structure supporting slope, can effectively reduce the impact of seismic waves on the slope and attenuate seismic waves to a certain extent compared with steel anchors. Furthermore, the BFRP anchors can be deformed in coordination with the slope, which can improve the overall working performance of the slope, especially limit the dynamic response of the middle and lower slopes. These results can provide a theoretical guide for the seismic design of BFRP anchors for high slopes.

\section{Introduction}

In the actual anchoring engineering, the conventional prestressed anchor shows a good antiseismic effect in low seismic intensity, which can limit the deformation of the rock mass and improve the stability of the slope $[1,2]$. However, the anchored rock mass deforms greatly under the strong earthquake condition, and it is generally difficult for the conventional prestressed anchors to continue limiting their deformation. In addition, the steel anchor is easily broken owing to its insufficient deformability or overload under the action of instantaneous impact load, causing slope instability and failure [3-5]. Furthermore, some corrosive chemicals in the groundwater and the slope body often cause aging, damage, or destruction of the conventional prestressed anchor tendon, which leads to the phenomenon of overall instability and destruction of the anchored slope. Although technical measures such as hot-dip galvanizing on the surface, epoxy coating, anchor bracket, and grouting slurry mixed with preservatives can be adopted in the anchoring engineering, the problem has not been fundamentally solved [6]. With the continuous improvement of infrastructure, the demand for steel bars is increasing. However, the iron ore resources used to produce steel bars are gradually being depleted. Therefore, a nonmetallic anchor should be adopted instead of the steel anchor for geotechnical anchoring engineering. The new material of basalt fiber-reinforced plastics (BFRP) is gradually used to 
replace the traditional reinforced anchor because it can fully utilize its relatively high tensile strength and low elastic modulus. In addition, the BFRP anchor has the advantages of good stress transfer characteristics, antiseismic and corrosion performance, which can better adapt to the deformation of the slope, effectively solve the corrosion problem of anchor in the slope; and has obvious antiseismic effect of the slope [5]. Basalt fibers are gradually gaining domestic acceptance owing to their advantages of environmental protection, corrosion resistance, high strength, light weight, fatigue resistance, good adhesion to the grouting body, thermal expansion coefficient similar to concrete, and tensile strength retention rate equivalent to steel bars.

Many researchers have done much scientific research on the mechanical properties, bond strength with cement mortar, and anchoring performance, and have obtained a lot of valuable results $[7,8]$. In previous studies, scholars have carried out a lot of research on the basic physical and mechanical properties of FRP rebars [9-13]. In their conclusions, the main factors that affect the degree of corrosion of FRP bars are temperature, humidity, salt solution, acidbase environment, ultraviolet intensity, etc., and it was found that the corrosion of FRP tendons is usually formed by the deterioration of the fiber or the matrix interface. Generally, basalt fiber has better resistance in acidic environment than alkaline environment $[14,15]$. Some researchers $[16,17]$ have conducted comparative studies on the corrosion resistance of BFRP, GFRP, and CFRP rebars, and considered that the corrosion resistance and durability of BFRP rebars are better than those of GFRP and CFRP rebars. Furthermore, Urbanski et al. [18] and Zhang et al. [19] studied the ductility, deformability, ultimate stress, and damage mechanism of BFRP-reinforced structures and compared with traditional steel-reinforced structures, indicating that BFRP-reinforced structures have certain advantages.

In recent decades, BFRP rebars are mostly used to reinforce concrete beams and supports [20,21]. Yuan et al. [22] studied the influence of the bond performance between the BFRP sheet and concrete, and proposed a bond strength model considering the influence of strain energy and BFRP bond area. Liu et al. [23] studied the bond behavior between BFRP reinforcement and recycled aggregate concrete (RAC) by the orthogonal test method, and proposed the influence of RAC strength grade, volume content, and length of chopped basalt fiber on the bond stress slip constitutive relationship. Nerilli and Vairob [24] studied the failure mode of the BFRP-bar-reinforced concrete support through the push-pull double-shear test of BFRP concrete specimens, and analyzed in detail the strain mode and the bondslip relationship between BFRP and concrete interface.

Owing to the mature performance and technology of BFRP rebars, it is gradually used in slope reinforcement engineering. Lei et al. [25] and Liu [26] carried out experiments to analyze the soil slopes supported by nonprestressed BFRP and FRP bolts, respectively, and proposed relevant values and recommended design parameters for the soil slopes supported by BFRP bolts. Jin et al. [27] and Ho et al. [28], respectively, proposed the use of GFRP and FRP to reinforce the slope, and the reinforcement effect was evaluated through numerical theory and experiment. Furthermore, Huang et al. [29, 30], and Kim and Lee [31] established models to predict the effect of slope reinforced by new composite materials, and the experimental results showed that the proposed prediction model achieved high prediction accuracy.

In the past, scholars' studies on BFRP mainly focused on its physical and chemical properties, bonding properties with concrete, and slope reinforcement. Despite many studies, dynamic response of BFRP-reinforced slopes under seismic loadings is mainly based on theoretical analysis and numerical simulation, and in some cases, the engineering practice for antiseismic design in reinforcing the slopes is still largely based on experience. Furthermore, the use of large-scale model tests to study the dynamic response characteristics of BFRP anchors in slope reinforcement engineering under earthquake action is still lacking. Therefore, to clarify the reinforcement effect of BFRP anchor cables in the protection of high slopes in high-intensity earthquake areas, the large-scale shaking table test was used to study the dynamic response characteristics and the failure mode of the slope strengthened by BFRP anchor (cable)+ frame structure. Meanwhile, the effect of the slope strengthened by BFRP was compared with that of traditional reinforced anchor (cable) + frame structure. The study results help us to better understand the dynamic response characteristics of BFRP-reinforced slopes and provide a scientific basis for the dynamic rational design of BFRP anchor cables to reinforce high slopes.

\section{Shaking Table Test Design}

2.1. Project Overview. In this study, the fully weathered basalt slope of the Xiangshui River $(\mathrm{K} 5+620 \sim \mathrm{K} 5+700)$ on the Gongdong expressway was selected as the experimental prototype. The geological disaster point along the Gongdong expressway and the location of the Xiangshui river slope are shown in Figure 1.

The slope of the Xiangshui river has a pile number of $\mathrm{K} 5+620,000 \sim \mathrm{K} 5+700,000$. It is located in Wool Meadows Village, Xundian County, with a total length of about $100 \mathrm{~m}$ and a course of approximately $13^{\circ}$. The terrain of the slope body where the section is located fluctuates greatly, with gullies developed and vegetation at both ends of the slope, and the stratum is fully weathered basalt. The slope body has sliding traces along the bedrock, and the sliding direction is $30^{\circ}$ from the direction of the line. It can be judged that there has been a history of sliding here. The gullies on the left side are close to the slope body, while the gullies on the right side are about $200 \mathrm{~m}$ away from the slope body, and the terrain on the right side is $5 \mathrm{~m}$ away from the slope body.

The slope is $36 \mathrm{~m}$ high, and the excavation slope is a tertiary slope. The height of the first grade is $16 \mathrm{~m}$, and the second- and third-grade slopes are $10 \mathrm{~m}$ with the design slope rates of $1: 0.75$ and $1: 1$, respectively. The renderings of the Xiangshui river slope before and after excavation are shown in Figures 2 and 3, respectively. 


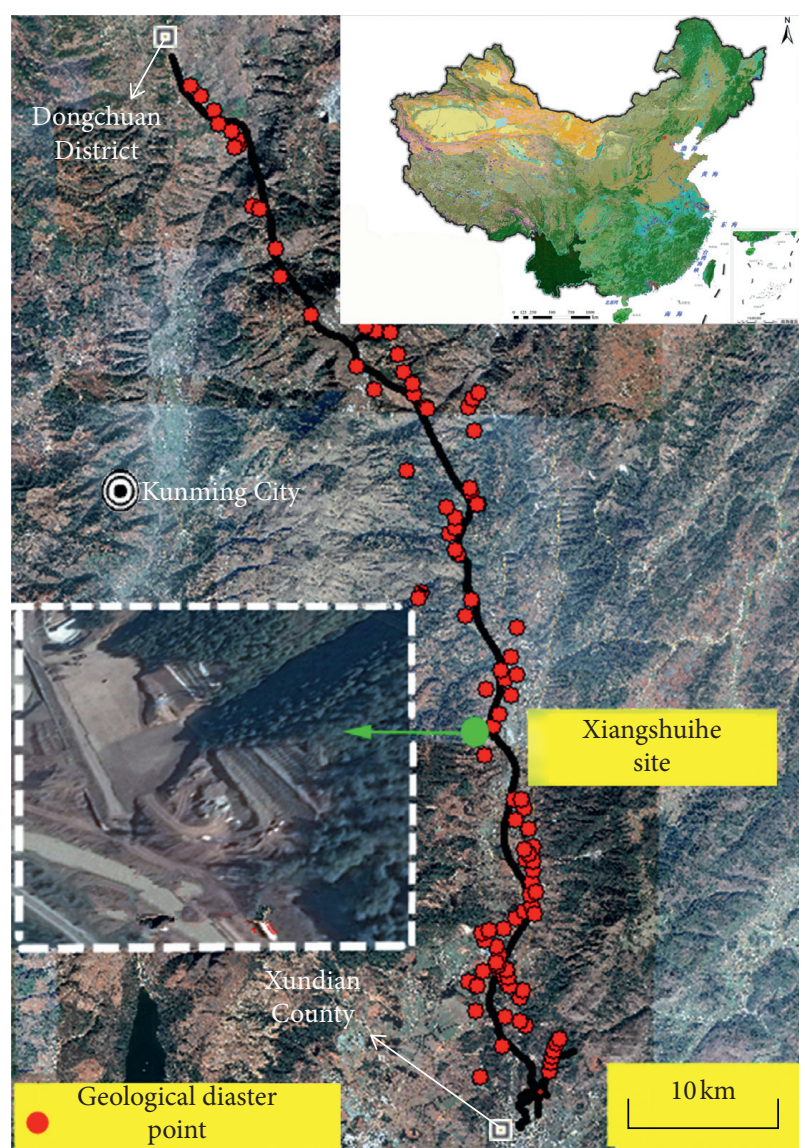

FIgURE 1: Geological disaster points along the Gongdong Expressway.

\subsection{Overview of Shaking Table and Boundary Treatment of the} Model Box. The shaking table test was conducted in the Loess Seismic Engineering Laboratory of Gansu Seismological Bureau. The shaking table of the laboratory is a vertical horizontal bidirectional shaking table of VPS 600ES 2, with a shaking table size of $4 \mathrm{~m} \times 6 \mathrm{~m}$. The maximum load mass is $25 \mathrm{t}$; the maximum displacement is $250 \mathrm{~mm}$ in the $\mathrm{X}$ direction and $100 \mathrm{~mm}$ in the $\mathrm{Z}$ direction; and the working frequency is $0.5-50.0 \mathrm{~Hz}$ [32].

In this shaking table model test, the rigid model box is used, which is welded with $2 \mathrm{~cm}$ thick steel plate and equilateral angle steel as its main frame. The inner groove size of the model box is $2.9 \mathrm{~m} \times 1.4 \mathrm{~m} \times 1.85 \mathrm{~m}$, and the long side of the model is made of $2 \mathrm{~cm}$ thick transparent glassfiber-reinforced plastic, which facilitates easy observation of the changes of the model [33], as shown in Figure 4. This test is a horizontal one-way vibration test, which uses a $2 \mathrm{~cm}$ thick steel plate for enclosure in the horizontal vibration direction of the model box. Owing to the seismic wave reflection on the boundary and the change of the system vibration form, a certain error will be brought to the test result, which is the so-called "model box effect". Since the rigid model box was used in this test, three measures have been taken to control the boundary condition design [34]: (1) Control the plane size of the structure model. (2) Coat the inner surface of the model box with petroleum jelly and set a

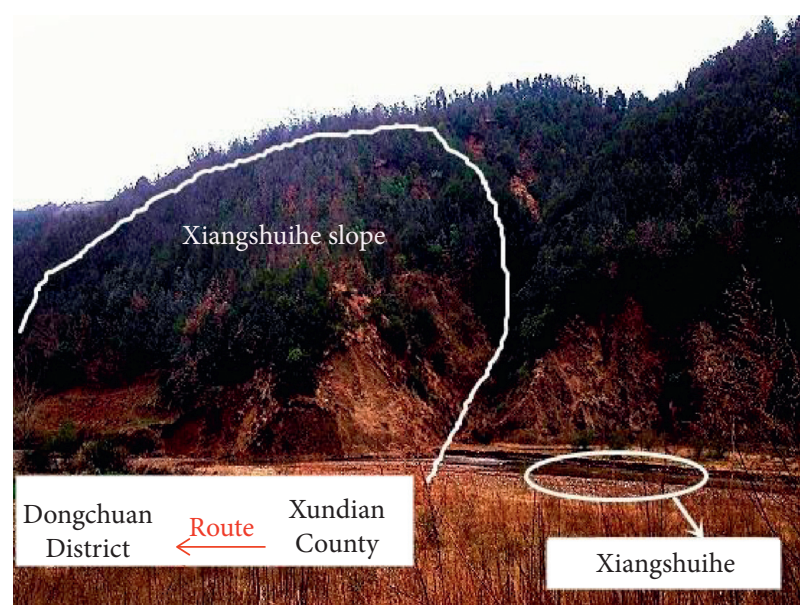

Figure 2: Xiangshui River slope before excavation.

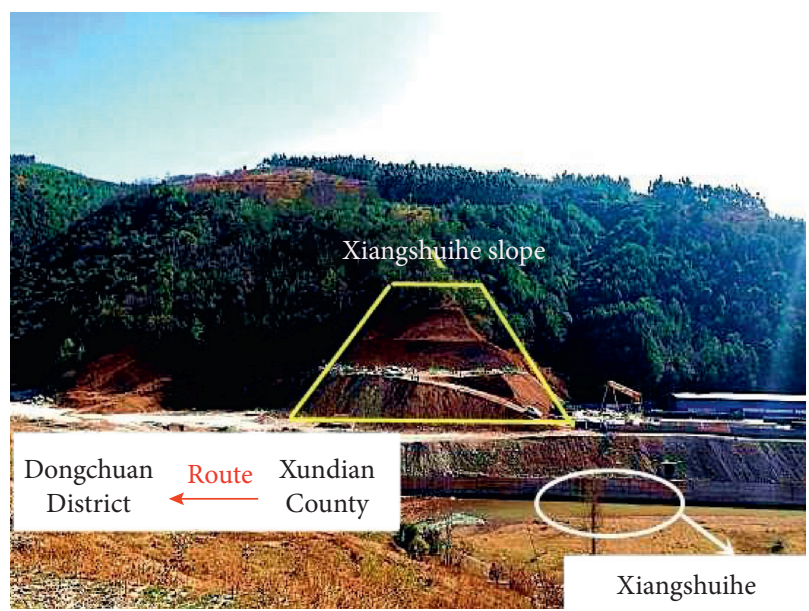

FIgUre 3: Xiangshui River slope after excavation.

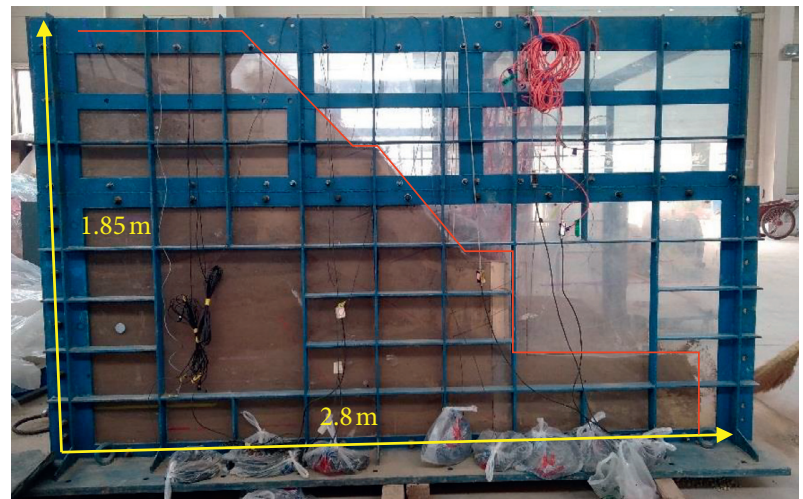

FIgURE 4: Schematic diagram of the model box.

foam layer on the side and back of the box. The foam layer mainly simulates the elastic support effect of the truncated medium soil on the finite field soil medium and provides partial damping, which reduces the seismic wave reflection effect on the model boundary. (3) To avoid the relative sliding between the soil and the bottom of the model box, a layer of $5 \mathrm{~cm}$ thick debris with a particle size of about $2 \mathrm{~cm}$ is 
laid on the model box bottom plate to increase the friction, and the bottom plate is treated as a friction boundary.

\subsection{Similar Relationship Design of the Shaking Table Model} Test. Owing to the limitation of the size of the shaking table, the input load, and the test site, it is almost impossible for the model size to completely conform to the prototype. Therefore, the usual shaking table tests are majorly scale tests, and the similarity between the prototype and the model is similar to that of the model test. The model test can achieve the expected results through comprehending and using the basic principles of the similarity theory correctly [35]. In the $1 \mathrm{~g}$ shaking table model test, the gravity acceleration of the model is consistent with the prototype. Therefore, the gravitational acceleration should be selected as a control parameter. The similarity ratio that the acceleration of gravity should satisfy is $C_{g}=1$ [36]. The " $1 \mathrm{~g}$ " environment refers to the conventional gravity environment relative to the centrifugal shaking test.

In general, the calculation of the similarity ratio between the prototype and the model can be obtained based on the dimensional analysis method. When the dimensional analysis method is used to derive the similarity relationship of the shaking table test, all parameters are included in a characteristic equation. Therefore, similar designs for soil, structure, and seismic waves cannot be achieved, respectively, and the deduction results require that each parameter meets the similarity ratio requirements when the model is similarly designed, which is almost impossible to achieve in physical model tests.

With reference to your suggestions and previous studies [37], we introduce a separate similar design method for soil-structure interaction model tests. After sorting all the physical quantities, the functional relation between the physical quantities can be written as follows:

$f=(L, \rho, g, \sigma, \varepsilon, E, A, F, m, u, \tau, G, I, c, M, a, t, \phi, \lambda, \gamma, \omega)$.

After the control parameters are selected, the similarity ratios of the other parameters can be derived from these three parameters. Equation (1) can be rewritten as

$$
f=\left(L, \rho, \frac{g}{\sigma}, \varepsilon, E, A, F, m, u, \tau, G, I, c, M, a, t, \phi, \lambda, \gamma, \omega\right) \text {. }
$$
follows:

The second separation of the characteristic equation is as

$$
\begin{aligned}
f_{\text {Soil }}^{\prime \prime} & =\left(L, \rho, \frac{g}{\sigma}, \tau, c, \phi\right), \\
f_{\text {Anchor cable }}^{\prime \prime} & =\left(L, \rho, \frac{g}{\sigma}, \varepsilon, E A, F\right), \\
f_{\text {Anchor cable }}^{\prime \prime} & =\left(L, \rho, \frac{g}{\sigma}, \varepsilon, E A, F\right) .
\end{aligned}
$$

By separating the parameters of the relevant characteristic equations of the soil-structure interaction model test, the single-value condition physical quantities can be divided into 4 types according to the importance of the model test: the control parameters with the highest weights, key parameters with larger weights, related parameters with smaller weights, and irrelevant parameters with the smallest weights, as shown in Table 1.

According to the above classification, the similar design of this experiment mainly analyzed the control parameters and key parameters, while ignoring the secondary parameters. To make the design of the test model reasonable and meet the size of the shaking table system, the similarity ratios of the control parameter geometrical size $L$, density, $\rho$ and acceleration $g$ are $C_{L}=20, C_{\rho}=1$, and $C_{g}=1$, respectively. The similarity ratios of other parameters can be derived from these 3 parameters, as shown in Table 2.

The "singularity" produced by some parameters is relatively large after calculation, and it is very difficult to make the model material fully meet the calculation requirements of similar scales in the model test. However, considering that the main purpose of this test is the acceleration response of the slope under earthquake action, not the slope itself, the secondary parameters of these similar materials can be ignored.

2.4. Model Test Materials. According to the geological survey data of the Xiangshui river slope, the overlying soil of the landslide prototype is mainly silty clay and gravel soil, the underlying rock layer is fully weathered basalt, and the bedrock is strongly weathered basalt. To be more in line with the engineering prototype, the design of the landslide of the model slope is carried out as the fully weathered basalt formation, and the base rock part of the slope is designed as the strongly weathered basalt formation. In the shaking table tests, the soil can be considered as having normal consolidation, which can neglect the influence of the difference in consolidation ratios of the prototype slope and the model slope under excavation conditions $[38,39]$. The physical and mechanical parameters of fully and strongly weathered basalts in the prototype slope are shown in Table 3.

For fully weathered basalt, the rock mass is very broken, and the bond strength between the blocks is not high. The test used river sand particles to simulate the slope rock blocks and the clay to simulate the cement between the rock blocks. Considering that there are many factors influencing the strength index of similar materials in rock and soil, this experiment adopted an orthogonal design method to perform direct shear test on the shear strength parameters of similar materials, using cohesive force and internal friction angle as the control indexes. Four mixing ratios were selected for the test, and the physical parameters obtained from the test are listed in Table 4. It should to be noted that the inherent cohesion is considered in the test, while the cohesion caused by the matrix suction is ignored. The neglect of this secondary parameter is within the allowable range.

The test results obtained in the model in Table 4 are calculated according to the similarity ratio and compared with the physical parameters of the fully weathered basalt in the prototype of the slope body to obtain Figure 5 . 
TABLe 1: Classification for variables by the importance degree.

\begin{tabular}{lccc}
\hline Parameter type & Soil & Anchor cable & Seismic wave \\
\hline Control parameters & $L, \rho, g$ & $L, \rho, g$ & $L, \rho, g$ \\
Key parameters & $\tau, c, \phi, \sigma$ & $\sigma, \varepsilon, E A, F$ & $a, t, \omega$ \\
Related parameters & $G, F, \lambda, \gamma, \varepsilon, m, a, u$ & $m, u$ & - \\
Irrelevant parameters & $E, I, A, M, t$ & $\tau, G, I, c, M, a, t, \phi, \lambda, \gamma, \omega$ & $\sigma, \tau, \phi, E, G, I, A, c, F$ \\
\hline
\end{tabular}

Here, $L$ is the length, $\rho$ is the density, $g$ is the gravity, $m$ is the mass, $a$ is the acceleration, $\sigma$ is the normal stress, $\tau$ is the shear stress, $\varepsilon$ is the strain; $\gamma$ is the shear strain; $c$ is the cohesion, $\phi$ is the internal friction angle, $E$ is the elastic modulus, $G$ is the shear modulus; $A$ is the area, $F$ is the pull out force, $u$ is the Poisson's ratio, $t$ is the time, $\omega$ is the frequency, $M$ is the bending moment, $I$ is the moment of inertia; and $\lambda$ is the damping ratio.

TABle 2: Model design similar parameters.

\begin{tabular}{lccc}
\hline Model composition & Physical quantity & Similarity & Similar parameters \\
\hline \multirow{4}{*}{ Soil } & Shear stress $\tau$ & $C_{\tau}=C_{\rho} C_{L} C_{g}$ & 20 \\
& Cohesion $c$ & $C_{C}=C_{\rho} C_{L} C_{g}$ & 20 \\
& Internal friction angle $\phi$ & $C_{\varphi}$ & 1 \\
& Normal stress $\sigma$ & $C_{\sigma}=C_{\rho} C_{L} C_{g}$ & 20 \\
Anchor cable & Normal stress $\sigma$ & $C_{\sigma}=C_{\rho} C_{L} C_{g}$ & 20 \\
& Strain $\varepsilon$ & $C_{\varepsilon}$ & 1 \\
& Tensile stiffness $E A$ & $C_{E A}=C_{\rho} C_{L}^{3} C_{g}$ & $20^{3}$ \\
Seismic wave & Pull out force $F$ & $C_{F}=C_{\rho} C_{L}^{3} C_{g}$ & $20^{3}$ \\
& Acceleration $a$ & $C_{a}=C_{g}$ & 1 \\
& Time $t$ & $C_{t}=C_{L}^{0.5} C_{\rho}^{-0.5}$ & 4.47 \\
\hline
\end{tabular}

TABle 3: Physical parameters of fully weathered basalt.

\begin{tabular}{lcccc}
\hline Item & Cohesion $(\mathrm{kPa})$ & Internal friction angle $\left(^{\circ}\right)$ & Compression modulus Es $(\mathrm{MPa})$ & Base friction coefficient $(\mu)$ \\
\hline Fully weathered basalt & 35 & 18 & 15 & 0.40 \\
Strongly weathered basalt & 50 & 20 & 42 & 0.50 \\
\hline
\end{tabular}

TABLE 4: Shear strength test results of material mix ratio (kg).

\begin{tabular}{lcccccc}
\hline Mix ratio & Cohesive soil & River sand & Gypsum powder & Water & Cohesion & Internal friction angle \\
\hline Mix ratio one & 1.5 & 2.5 & 0.19 & 0.2 & 2.0 & 14.93 \\
Mix ratio two & 1.0 & 3.0 & 0.5 & 0.37 & 2.0 & 31.0 \\
Mix ratio three & 1.5 & 3.0 & 0.3 & 0.3 & 1.6 & 14.97 \\
Mix ratio four & 1.5 & 3.0 & 0.3 & 0.4 & 2.4 & 12.69 \\
\hline
\end{tabular}

From Figure 5, the cohesive force and internal friction angle, which are measured by mix ratio three, are closer to the physical and mechanical parameters of the fully differentiated basalt. Therefore, the rock mass is simulated according to the mixing ratio of clay, river sand, gypsum, and water in a mass ratio of $5: 10: 1: 1$. The material densities of the fully and the strongly weathered strata were $2.04 \mathrm{~g} / \mathrm{cm}^{3}$ and $2.26 \mathrm{~g} / \mathrm{cm}^{3}$, respectively. During the model filling process, different compaction times of the soil body can be controlled and filled according to the different weathering degrees of the base rock and the sliding body of the stratum model. To ensure the continuity of the sliding process of the model slope, the Teflon film is used to simulate the sliding belt in this test, and the viability of using Teflon plastic to simulate the sliding belt in the shaking table test is verified by some experts $[34,40]$.

Considering that prestressed anchors are more difficult to implement in the model tests, it is difficult to find a suitable anchorage simulation material based on the $1: 20$ similarity ratio in the selection of similar materials for anchors. Since the test mainly studies the dynamic slopefixing effect of BFRP anchors and steel anchors, the prestressed anchors used in the prototype slopes are all $4 \mathrm{~mm}$ diameter BFRP and steel anchors. In addition, the exposed length of the anchor is $10 \mathrm{~cm}$, which is used to install the frame and anchor. The antislide pile is simulated by a pine pile with a cross-sectional size of $8 \mathrm{~cm} \times 6 \mathrm{~cm}$, a pile length of $80 \mathrm{~cm}$, and the lengths of the cantilever section and the embedded sections are $40 \mathrm{~cm}$. Furthermore, we drilled holes at positions $10 \mathrm{~cm}$ and $20 \mathrm{~cm}$ away from the top of the antislide pile, with a hole diameter of $4 \mathrm{~mm}$, as reserved holes for the two anchor cables passing through the lowermost layer of the slope, as shown in Figure 6(a). During the filling process of the model, the antislide piles in the left and right slopes were fixed first, followed by filling layer by layer, and then the steel and the BFRP anchor cables were implanted in the left and the right slopes, respectively. What we need to clarify is that the angle between the anchoring cables and the horizontal plane is $20^{\circ}$, and the anchor cables should be 


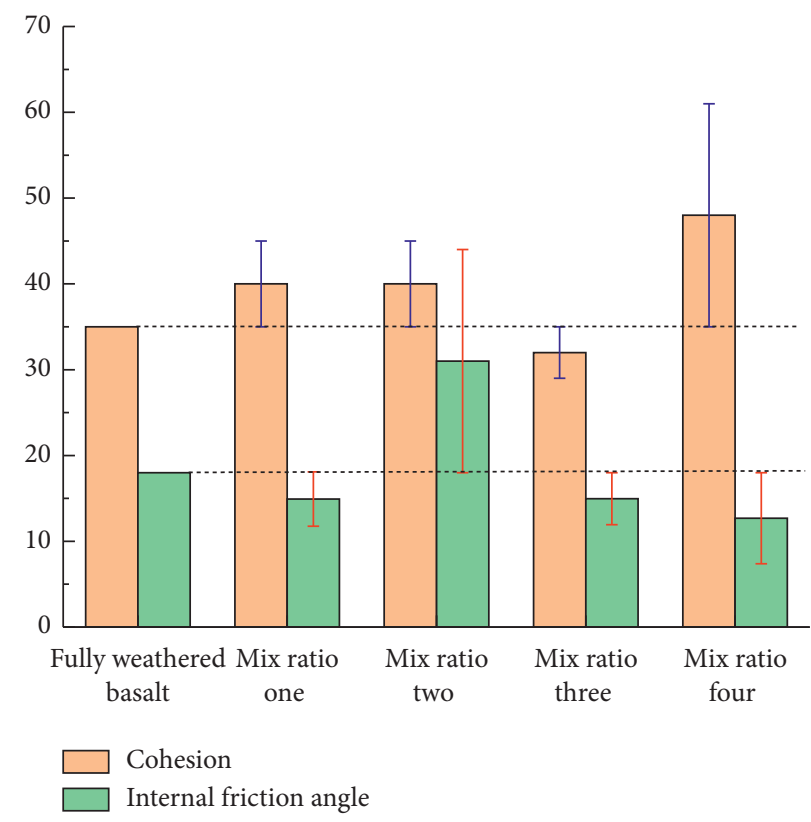

Figure 5: Comparison of physical parameters of each mix ratio.

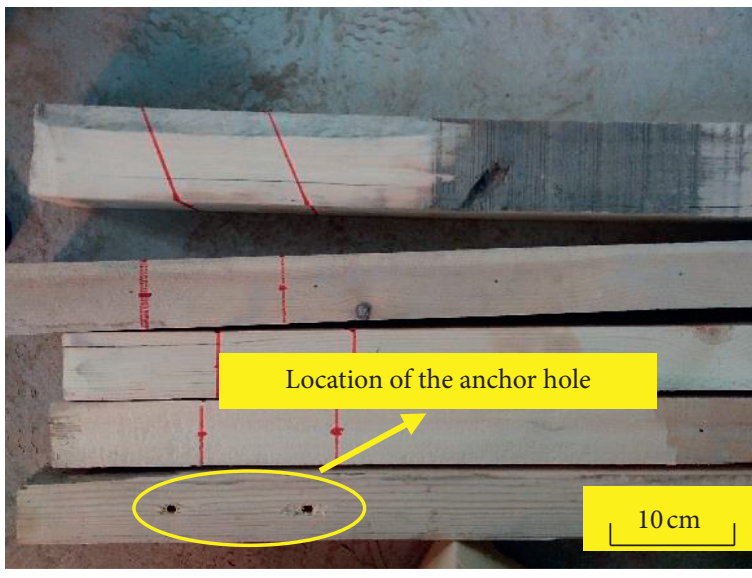

(a)

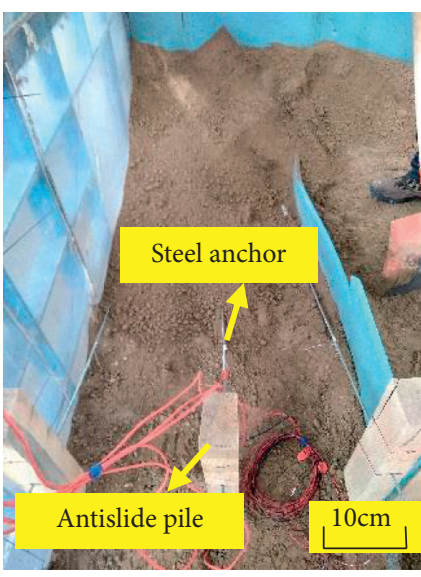

(b)

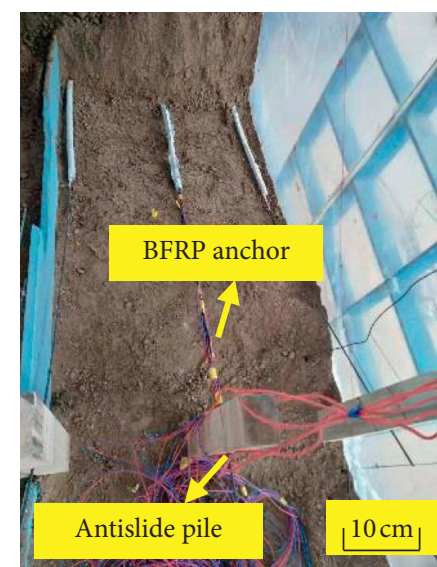

(c)

FIgURE 6: Schematic diagram of materials for model slope body. (a) Antislide pile. (b) Left slope steel anchor cable. (c) Right slope body BFRP anchor cable.

straight and not bent when inserting it into the reserved hole of the antislide pile. The implantation process of the anchor cables on the two antislide piles on the left and right slopes is shown in Figures 6(b) and 6(c).

2.5. Model Making and Measuring Point Layout. During the filling process, the steps of layered filling and layered tamping are used. Each layer is filled with a thickness of approximately $20 \mathrm{~cm}$, and the ramming times of the sliding bed exceed that of the sliding body. A Teflon plastic film is used to simulate a sliding belt at the interface of the sliding bed and the sliding body. The anchor is placed in advance during the slope body filling process and the anchors should pass through the Teflon film hole. In this test, a $5 \mathrm{~cm}$ thick polystyrene shock-proof foam was used in the middle to divide the model into two panels to prevent the interaction between the models. The left piece was an antislide pile + steel anchor + frame structure to reinforce the slope, while the right piece was an antislide pile+BFRP anchor + frame structure to reinforce the slope. The filling process of the model is shown in Figure 7.

The acceleration sensor used in the test was a DH301 three-phase capacitive acceleration sensor, and the detailed parameters of the acceleration sensor are listed in Table 5.

A total of 15 acceleration sensors were employed in this experiment; one acceleration sensor was arranged on the shaking table and 7 acceleration sensors were arranged on each of the two left and right slopes, as shown in Figure 8. Acceleration monitoring section I is set in the middle of the second-grade slope, whereby 3 acceleration sensors are arranged vertically, and 4 acceleration sensors are arranged 


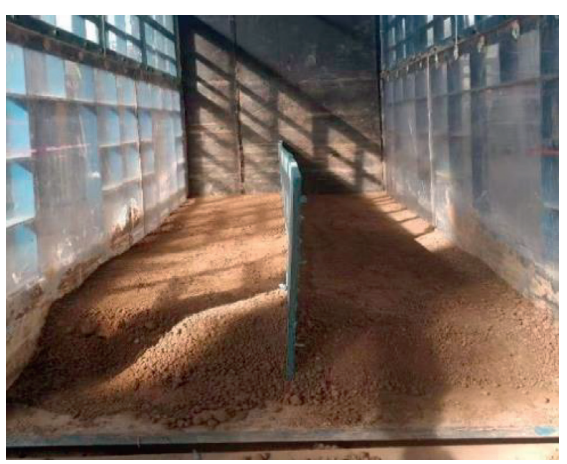

(a)

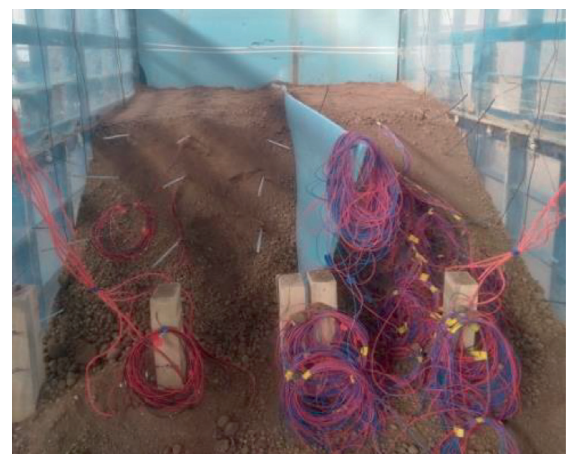

(b)

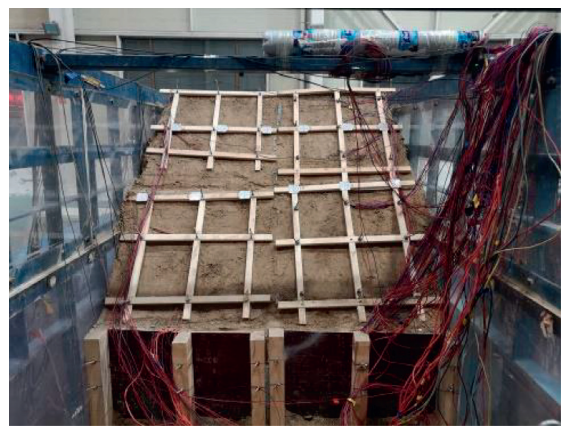

(d)

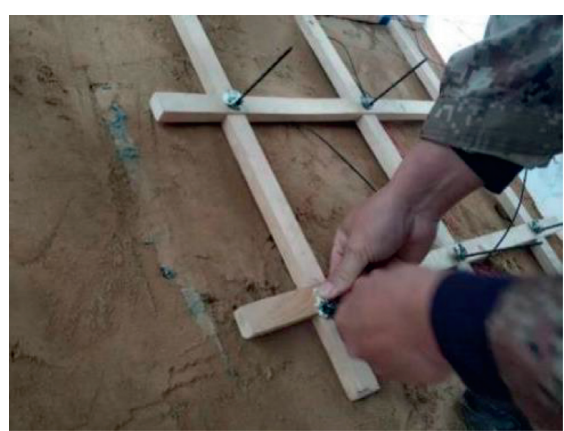

(c)

Figure 7: Filling process of test model. (a) Model material filling. (b) Anchor arrangement. (c) Frame installation and locking. (d) Model production completed.

TABLE 5: Main technical indicators of DH301 series three-way capacitive acceleration sensor.

\begin{tabular}{lccc}
\hline Model & DH301 & Numbering & 121005 \\
\hline Sensitivity $\left(\mathrm{mV} / \mathrm{m}^{-2} \mathrm{~s}^{-2}\right)$ & $X$ axis: 66.3 & Frequency range $(\mathrm{Hz})( \pm 3 \mathrm{~dB})$ & $X / Y$ axis: $0 \sim 1500$ \\
Range & $Y / Z$ axis: 66.8 & Install resonance & $Z$ axis: $0 \sim 800$ \\
Acceleration overload & $\pm 20 \mathrm{~m} / \mathrm{s}^{2}$ & Lateral sensitivity & $12 \mathrm{kHz}$ \\
Supply voltage & $5 \times 10^{4} \mathrm{~m} / \mathrm{s}^{2}$ & Input & $<5 \%$ \\
Operating temperature & $\mathrm{DC} 8 \mathrm{~V} \sim \mathrm{DC} 16 \mathrm{~V}$ & weight & Side \\
Installation method & $-20 \sim 80^{\circ} \mathrm{C}$ & Dimensions & $\sim 9 \mathrm{~g}$ \\
& Bonding & & $13 \times 15 \times 8 \mathrm{~mm}$ \\
\hline
\end{tabular}

vertically in section II. The position of the left slope sensor is the same as that of the right slope, and the acceleration sensor numbers in the left slope are L1-L7 (R1-R7 in the right slope) in corresponding order. Since only the horizontal seismic action is loaded in this test, only the horizontal channel of the sensor is used in the test.

2.6. Design of the Test Loading Scheme. The seismic wave employed in this test is the form widely used by scholars in the field of seismic research globally, that is, the EL-Centro wave. This wave was the first seismic wave with a maximum acceleration of more than 300 gal captured in the United States in 1940 [41]. In the shaking table test, if the time compression ratio of seismic wave is less than $1: 3.16$, it will cause the seismic wave spectral components to be too complex and produce distortion, which will lead to adverse effects on the acquisition and processing of test data [42]. The seismic waves in the test were not compressed in a similar ratio, and the original wave of the EL-Centro wave was input during the test. The acceleration time history curve of the EL-Centro wave at the measuring point of the shaker table when the peak value of the input wave was $0.1 \mathrm{~g}$ (case 1) is shown in Figure 9(a). The sampling interval was $0.00156 \mathrm{~s}$, and the main vibration time was approximately 25-65 s, a total of $40 \mathrm{~s}$. In addition, the excellent frequency of the Fourier spectrum is $1.0-2.5 \mathrm{~Hz}$, and the maximum amplitude is approximately 0.015, as shown in Figure 9(b).

Since horizontal earthquakes are the main cause of landslides and damage to the retaining structures, ELCentro waves were used in the X-direction loading method in this shaking table test [43]. To determine the influence of the changes in the slope natural vibration frequency and damping ratio on the dynamic parameters of the test model during the test, a sine sweep frequency of $0.05 \mathrm{~g}(0.1-50 \mathrm{~Hz})$ was input when the acceleration peaks before and after the test changes.

There are 10 working conditions in this test (excluding the white noise). To meet the seismic design requirements of 


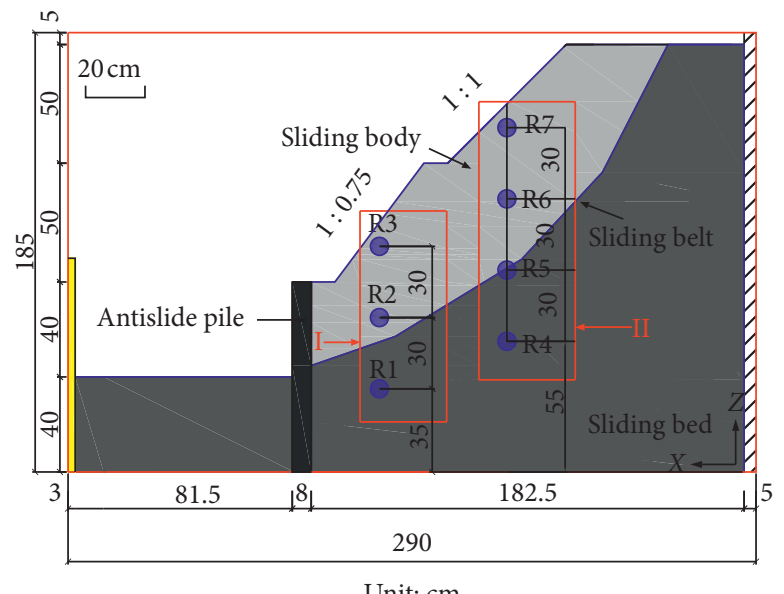

Accelerometer

FIGURE 8: Layout of acceleration sensor.

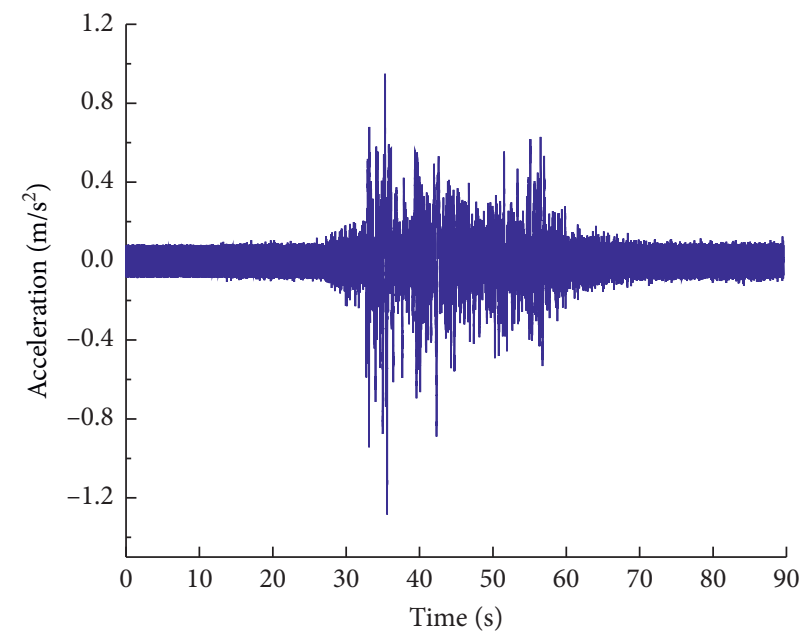

(a)

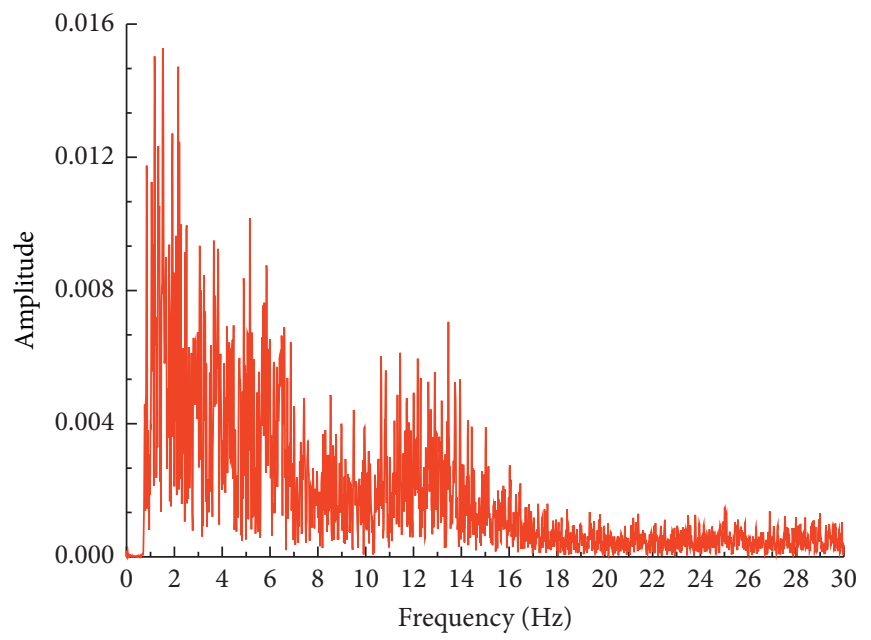

(b)

FIGURE 9: EL-Centro wave acceleration time history curve and Fourier spectrum. (a) EL-Centro wave acceleration time history curve. (b) EL-Centro wave Fourier spectrum.

the prototype area, the peak values of input waves are 0.1 (0.15), $0.2,0.3$, and $0.4 \mathrm{~g}$, respectively. In addition, to explore the failure mode of the slope model under the action of strong earthquakes, seismic wave excitations of $0.6 \mathrm{~g}, 1.0 \mathrm{~g}$ and $1.4 \mathrm{~g}$ were, respectively, designed to load the model. The loading system is shown in Figure 10.

\section{Analysis of Test Results}

3.1. Analysis of the Acceleration Amplification Factor. To study the amplification effect of the slope response acceleration, the acceleration amplification factor (PGA) in the slope body is defined as the ratio of the peak acceleration value at each measuring point to the peak acceleration value of the vibration table. We considered the acceleration magnification factor of R7 measuring point of section II in the right slope as an example. Suppose the maximum value in the acceleration time-history curve of R7 measuring point under a certain seismic wave is max (R7), while the maximum value in the acceleration time history curve is max (table), then the acceleration amplification factor $\alpha$ is

$$
\alpha=\frac{\max (R 7)}{\max (\text { table })} .
$$

The relationship between the acceleration amplification factor of the BFRP and the steel anchors supporting the slope and the peak value of the input seismic wave under the action of the horizontal EL-Centro wave in each working condition is shown in Figures 11 and 12. With the increase in the peak value of the input wave, the acceleration amplification factors of sections I and II in the left and right slopes have obvious segmentation, which can be divided into (1)-(5) stages. When the peak value of the input wave is not greater than $0.2 \mathrm{~g}$, that is, under the excitation of the small amplitude of seismic waves, the stress state of the slope body 


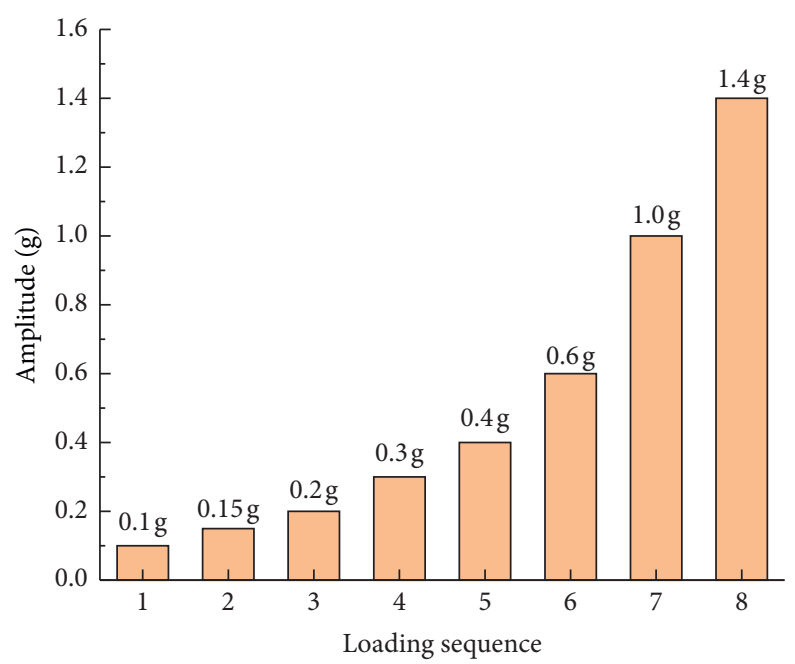

EL-Centro wave (horizontal)

Figure 10: Schematic diagram of the loading system.

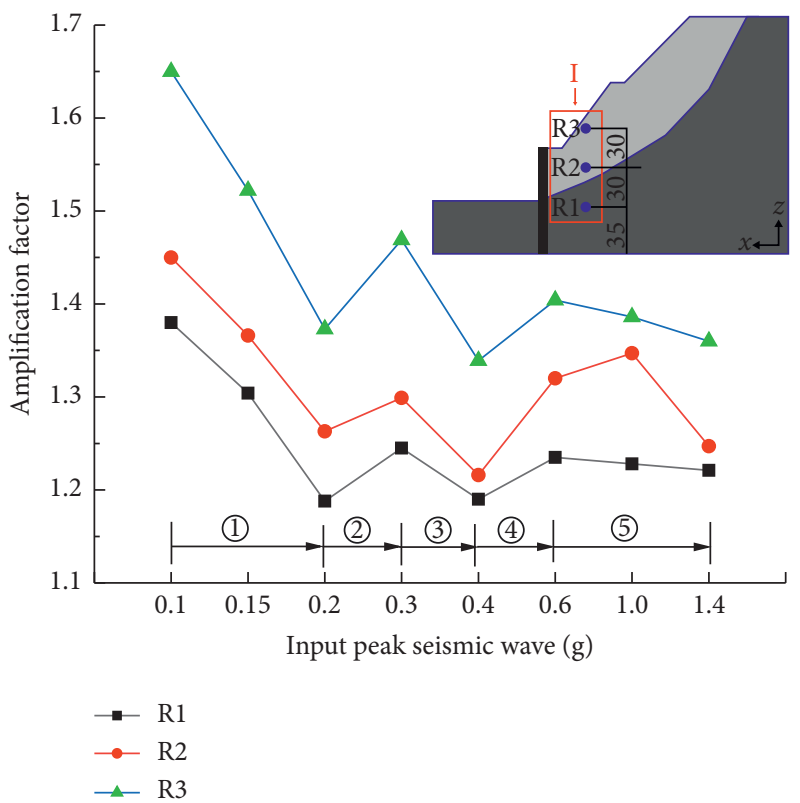

(a)

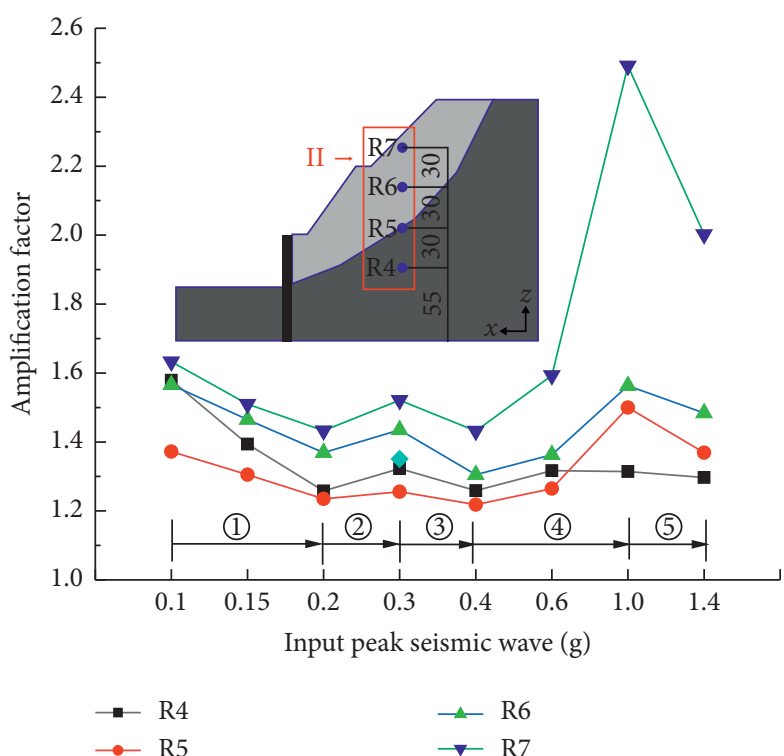

(b)

FIGURE 11: Relationship between acceleration coefficient of the right slope acceleration and the peak value of input wave. (a) Section I acceleration amplification factor. (b) Section II acceleration amplification factor. (1) Elasticity; (2) Plasticity; (3) (Potential) Sliding Surface; (4)Plastic enhancement; (5) Destruction.

is at stage (1). It can be considered that the slope body is basically in the elastic stage, and the acceleration amplification factor of each measurement point follows the peak value of the input wave. The increase shows a linear decreasing trend. When the peak value of the input wave is $0.2 \mathrm{~g} \sim 0.3 \mathrm{~g}$, it can be considered that the slope body is in the plastic stage ((2)), and the acceleration amplification factor changes from a strong elastic characteristic to a strong plastic characteristic. Meanwhile, when the peak value of the input wave is $0.2 \mathrm{~g}$, the relationship between the acceleration amplification factor of each measuring point and the peak value of the input wave shows a "sawtooth" distribution. This is because after the action of the $0.2 \mathrm{~g}$ seismic wave, the slope body was partially destroyed, and the change in the slope geometry and the force status had an impact on the propagation law of acceleration. When the peak value of the input wave is $0.3 \sim 0.4 \mathrm{~g}$, the slope body is in stage (3). With an increase in the peak value of the input wave, the acceleration magnification coefficient of each measuring point decreases sharply. This indicates that in this process, the dynamic shearing of the modulus decreases, the damping ratio increases, and a sliding surface or potential sliding 


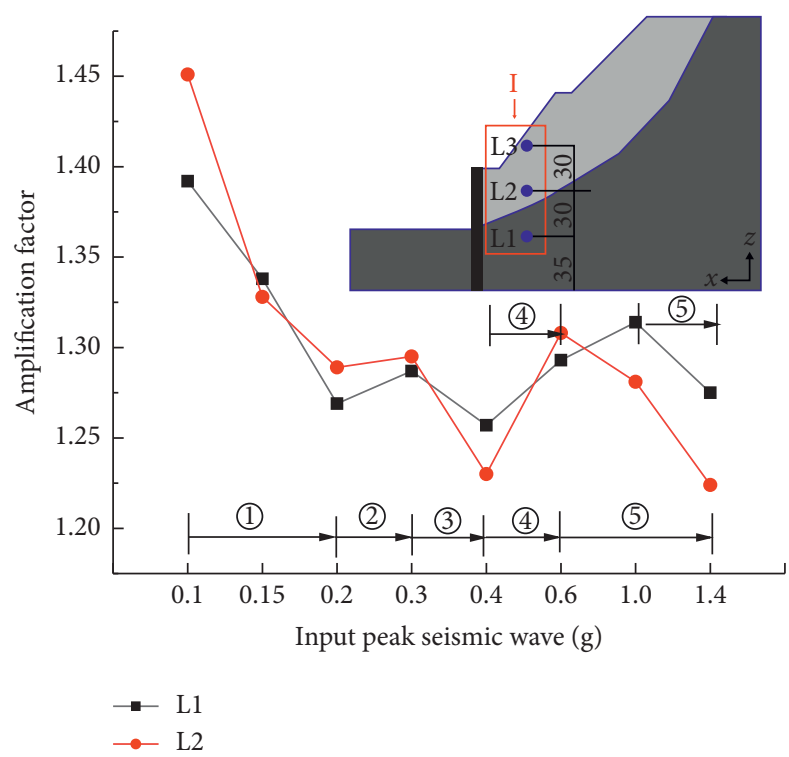

(a)

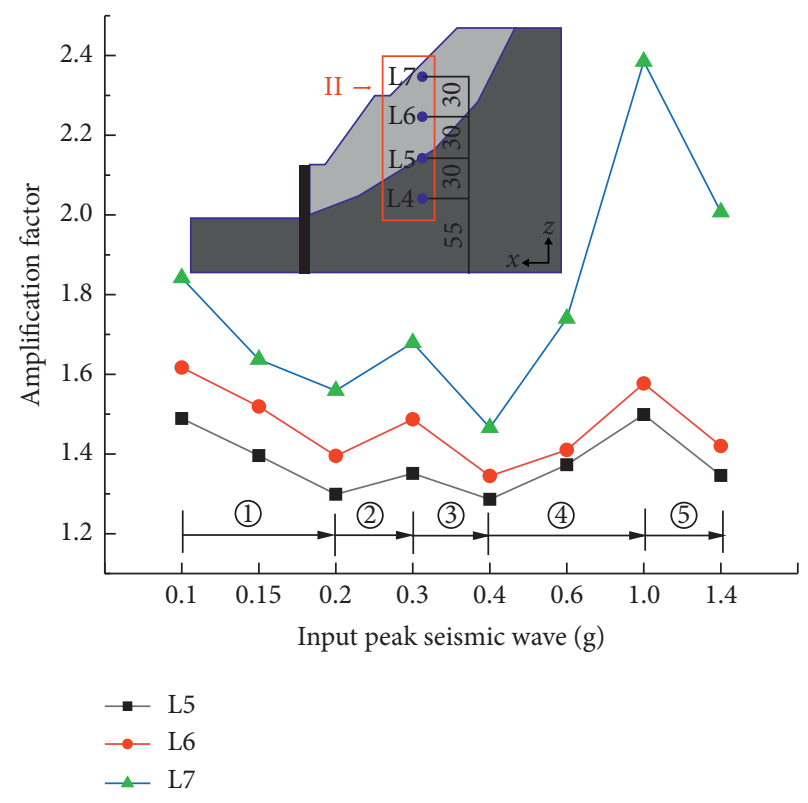

(b)

FIGURE 12: Relationship between the acceleration coefficient of the left slope acceleration and peak value of the input wave. (a) Section I acceleration amplification factor. (b) Section II acceleration amplification factor. (1) Elasticity; (2) plasticity; (3) (potential) sliding surface; (4) plastic enhancement; (5) destruction.

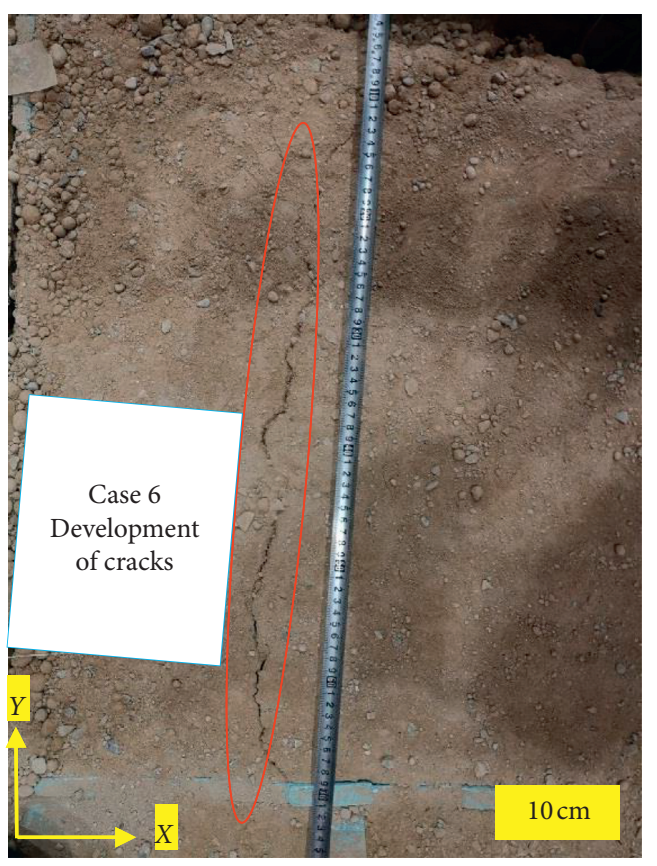

(a)

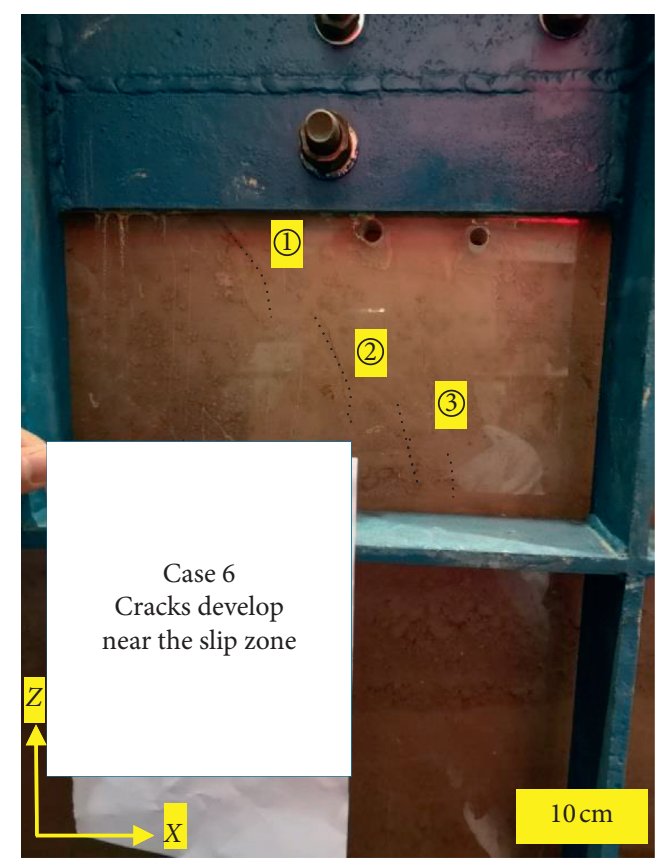

(b)

Figure 13: Schematic diagram of cracks on the left and right sides of the slope. (a) Lateral cracks on the right-side slope of $0.6 \mathrm{~g}$. (b) Diagonal crack on the left-side slope of $0.6 \mathrm{~g}$.

surface may be generated in the slope, which is consistent with the study of Chen Chen et al. [44]. For monitoring section I, when the input wave peak value is $0.4 \mathrm{~g} \sim 0.6 \mathrm{~g}$, the slope body is in a plastically strengthened state $((4))$; when the input wave peak value is $0.6 \mathrm{~g} \sim 1.4 \mathrm{~g}$, the slope body is in the destruction stage $((5))$. For monitoring section II, the slope body is in a plastically enhanced state during the process when the input wave peak value is $0.4 \mathrm{~g}-1.0 \mathrm{~g}$; ((4)) when the input wave peak value is $1.0 \mathrm{~g} \sim 1.4 \mathrm{~g}$, the slope body is in the stage of destruction $((5))$.

From Figures 11(b) and 12(b), the magnification factors of the measurement points R5 (L5), R6 (L6), and R7 (L7) under 


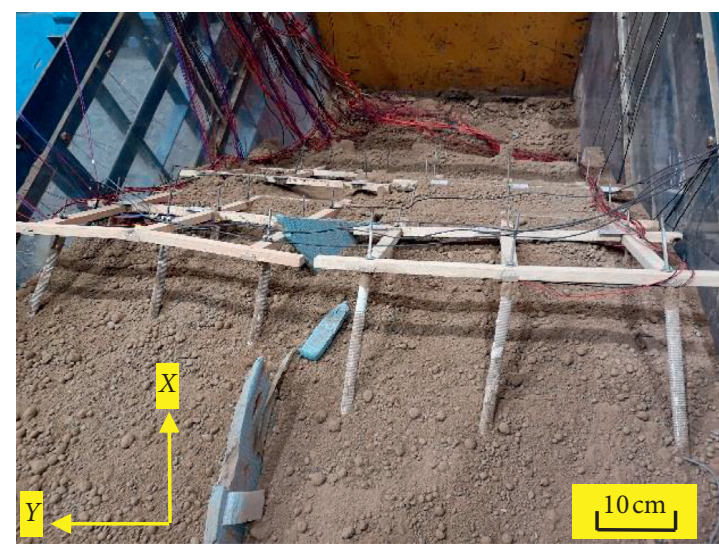

(a)

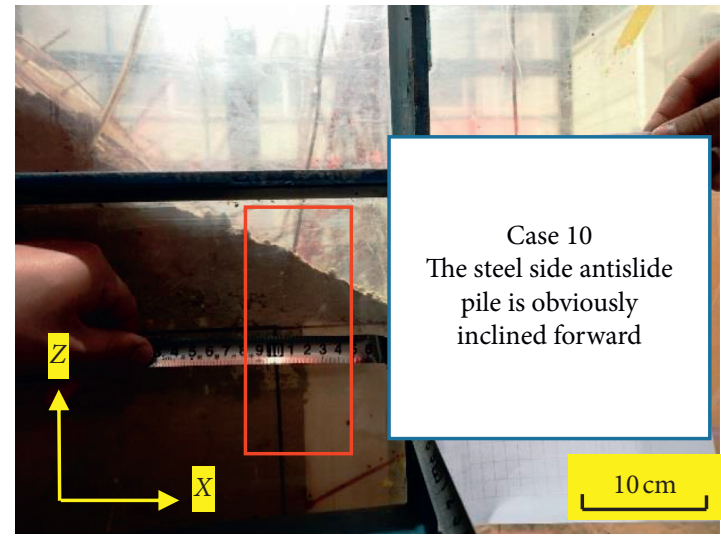

(c)

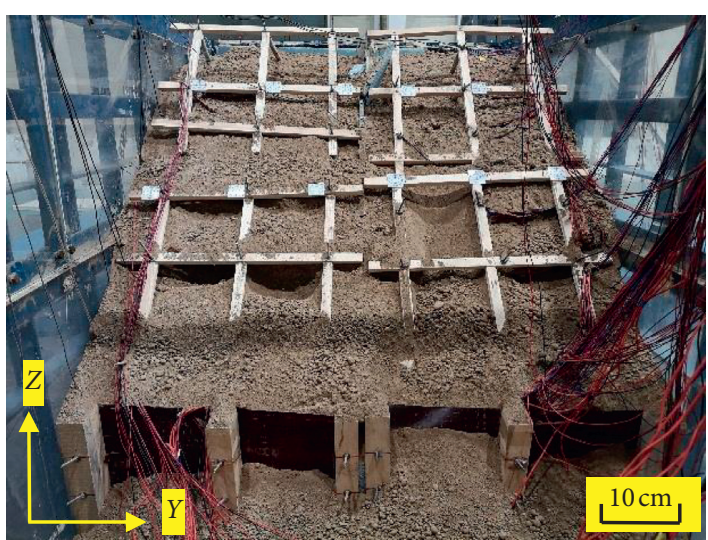

(b)

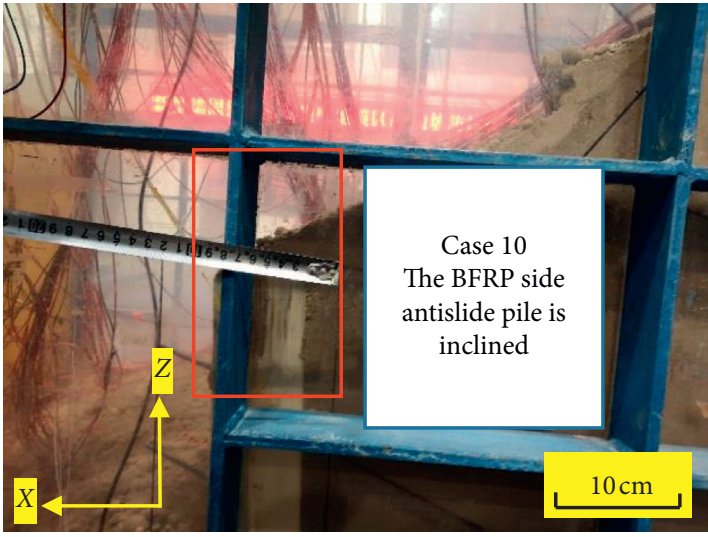

(d)

FIGURE 14: Deformation of anchor rod and antislide pile. (a) $1.4 \mathrm{~g}$ bolt exposed. (b) $1.4 \mathrm{~g}$ slope flow phenomenon. (c) $1.4 \mathrm{~g}$ left slope antislide pile tilt. (d) $1.4 \mathrm{~g}$ right slope antislide pile tilt.

the action of a seismic wave of $0.4 \mathrm{~g}-1.0 \mathrm{~g}$ increase again, and the increase in the acceleration amplification factor at the measuring point R7 (L7) at the top of the monitoring section II is particularly evident, indicating that after the action of the $0.4 \mathrm{~g}$ seismic wave, the left and right sides of the slope slip zone and the slope body at the position of the sliding body began a further deformation stage. This deformation phenomenon should mainly be reflected by the collapse of the soil at the top of the slope. When the peak value of the input wave is $1.4 \mathrm{~g}$, the acceleration amplification factor values of the measuring points R5 (L5), R6 (L6), and R7 (L7) are significantly reduced. Combined with the analysis of the test phenomenon, it can be observed that the slope surface flow, antislide pile top displacement, and other phenomena appear on the slope body, which indicates that the slope body has suffered serious damage under the action of seismic waves in this working condition.

Based on the above analysis, the deformation state of the slope supported by steel and BFRP anchors is consistent under the earthquake action of various working conditions. To analyze the dynamic response of the slope body at the main deformation stage, $0.15 \mathrm{~g}, 0.4 \mathrm{~g}$, and $1.4 \mathrm{~g}$ working conditions of the slope body under elastic, plastic, and failure conditions, respectively, are selected as the characteristic working conditions. These three working conditions are regarded as low, medium, and strong earthquakes, respectively.
3.2. Slope Failure Analysis. During the test, the deformation of the two left and right slopes was recorded in the form of photos and sketches, as shown in Figures 13-15. After the seismic wave input of $0.3 \mathrm{~g}$, the slope supported by the right BFRP anchor did not show obvious damage, but the slope supported by the left steel anchor the phenomenon of soil seismic subsidence appeared in the third-grade slope. Under the action of a seismic wave with a peak input acceleration of $0.6 \mathrm{~g}$, the lateral cracks on the top of the right slope under the action of $0.4 \mathrm{~g}$ of seismic wave continued to develop. After the $0.6 \mathrm{~g}$ seismic wave loading was completed, the crack length was $45 \mathrm{~cm}$, which was an increase from the original $15 \mathrm{~cm}$, and the crack width also increased, as shown in Figure 13(a). In addition, under the action of a $0.6 \mathrm{~g}$ seismic wave, the slope body supported by the left steel anchors had three parallel diagonal cracks at the position of the secondary slope slip zone, all of which were oriented toward the foot of the slope, as shown in Figure 13(b).

When the input wave peak value is $1.4 \mathrm{~g}$, the left and right slope bodies are damaged in different degrees. The exposed length of the steel bolt at the top of the left slope reaches $14 \mathrm{~cm}$, and the exposed length of the BFRP bolt is smaller than that of the steel bolt (about $8 \mathrm{~cm}$ ), as shown in Figure 14(a). Furthermore, the slope flow phenomenon appeared on the surface of the two slopes, a large amount of 


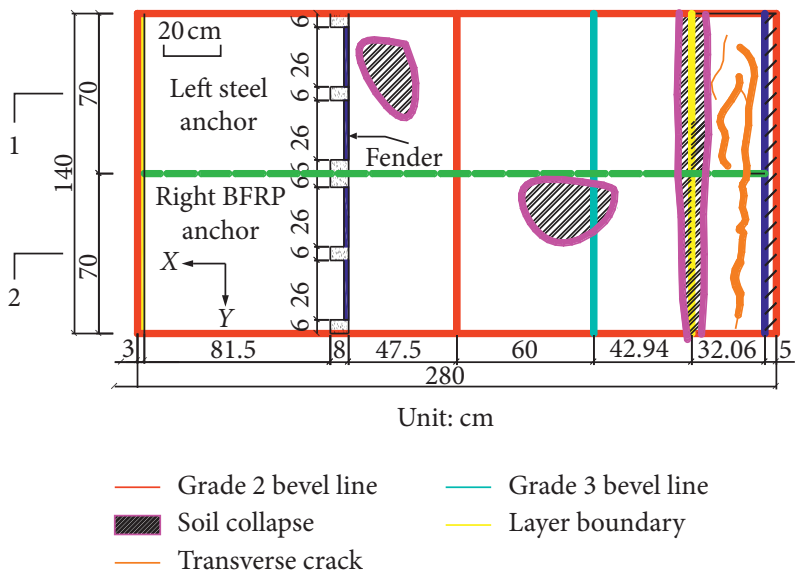

(a)

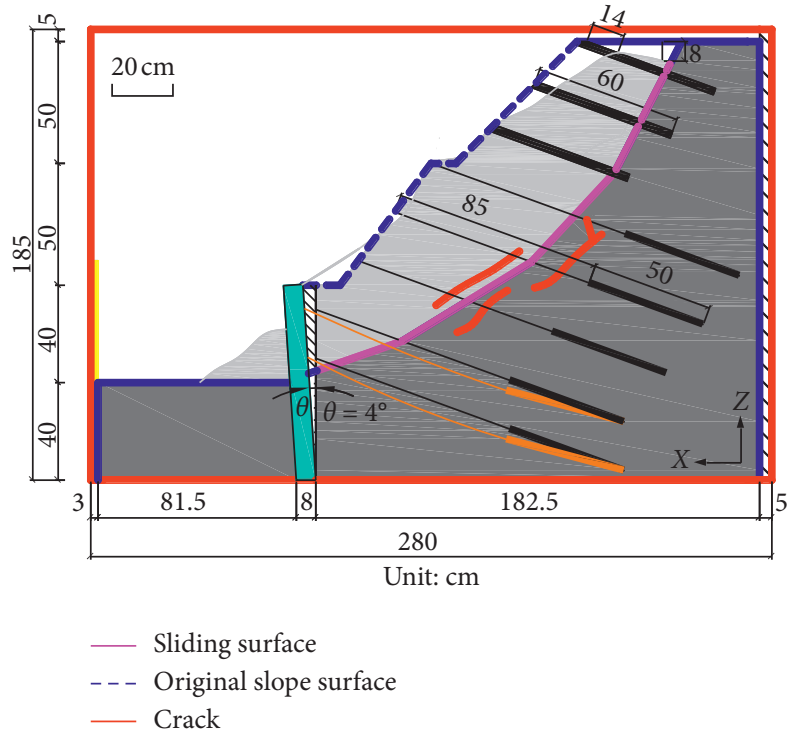

(b)

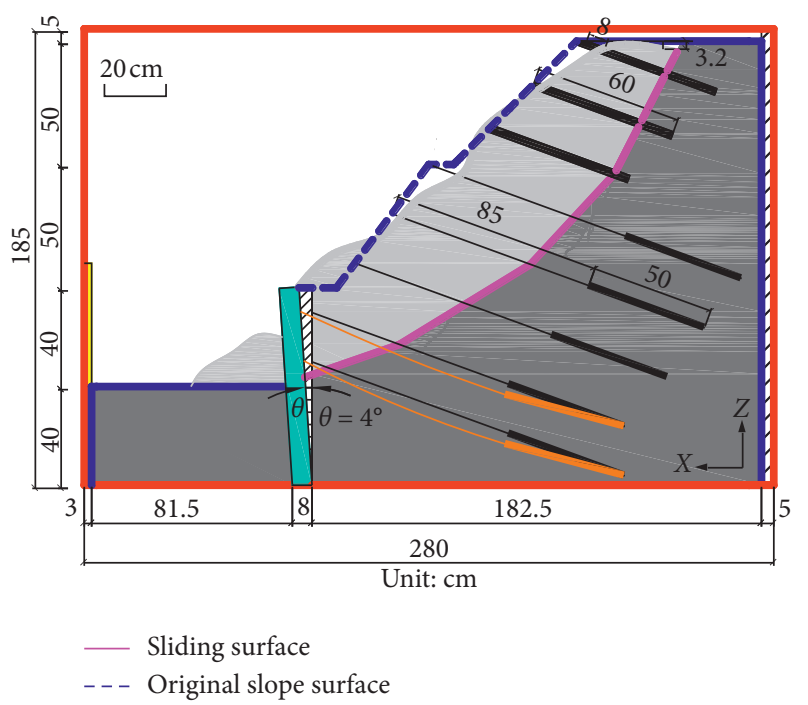

(c)

Figure 15: The final deformation of the slope. (a) Top view of slope deformation. (b) Deformation of the right slope. (c) Deformation of left slope.

soil on the slope body was peeled and collapsed, and the slope flow supported by the right BFRP anchor was mainly manifested in the middle of the slope. At the lower position, the slope flow supported by the left-side steel anchors is mainly reflected at the upper position of the slope, as shown in Figure 14(b). It can be observed from Figure 14(c) and $14(\mathrm{~d})$ that under the action of a seismic wave of $1.4 \mathrm{~g}$, the antislide piles of the two left and right slopes have a forward tilt phenomenon, and the displacement of the pile top is approximately $2 \mathrm{~cm}$.

The failure process of the anchors under the action of an earthquake is first that the axial force of the anchors reaches the limit and yields, and then the sliding body undergoes a large horizontal deformation, which causes the anchors to be damaged by a large shear force at the weak structural surface. It also exacerbates the development of horizontal deformation of the sliding body and eventually leads to the failure of the anchor-supported slope. However, the protective mechanism of BFRP anchors and steel anchors when reinforcing the slope is slightly different:

(1) The slope protection mechanism of steel anchors under seismic loadings is that the steel anchors produce restraint forces on the shear deformation and relative displacement of the slope. This restraint mainly includes preventing the slope body from sliding along the weak surface, preventing shear failure surface in the slope body, and preventing relative rotation of the blocks in the slope. Therefore, steel anchors can well limit the deformation of the rock mass and improve the stability of the slope in the case of low seismic intensity. 
However, under the conditions of strong earthquakes, the anchored rock mass deforms greatly, and it is generally difficult for conventional prestressed steel anchors to continue to limit its deformation. At this time, the anchors as the rigid structure are easy to be broken owing to their insufficient deformation capacity or overload under instantaneous impact load, leading to slope instability. Therefore, the BFRP is used to replace the traditional steel anchors.

(2) The slope protection mechanism of BFRP anchors under seismic loadings is to make full use of its relatively high tensile strength and low modulus of elasticity, increase the shear strength of the anchor, improve the stress state of the slope, and make the anchor have better stress transfer characteristics. In addition, when the anchors are damaged under the action of an earthquake, BFRP anchors as the flexible structure can allow the slope to appear as proper displacement, and the flexibility and ductility of the anchor can coordinate the deformation of the slope. Furthermore, BFRP anchors can consume part of the seismic wave energy through multiple refraction and reflection of seismic waves, resulting in a smaller impact of seismic waves on BFRP anchors' supporting slopes.

In addition, the macroscopic damage phenomenon during the test in Figure 15 also shows that the two supporting structures have different protection mechanisms. Figure 15(a)15(c) are the final deformation of the top of the slope, left slope and right slope, respectively. It can be obtained from Figure 15(a) that three transverse tension cracks appear on the left slope at the embedding position of the sliding belt on the top of the slope, and the strike of the cracks is parallel, while a transverse tension crack appears on the top of the right slope, which connects with the widest transverse crack on the left slope. At the same time, by comparing Figure 15(b) and 15(c), there are three diagonal cracks near the sliding zone after the secondary slope of the left slope, while there are no obvious oblique cracks along the slip zone of the right slope, and it is found that the soil collapse at the top of the left slope is more serious. Furthermore, the exposed length of the BFRP anchors are smaller than that of the steel anchors when the slope is finally damaged, which shows that the BFRP anchors can improve the stability of the slope in support engineering and make the overall working performance of the slope better.

\section{Discussion}

4.1. Analysis of Changes in Acceleration Response Spectrum. For the acceleration measurement points, the data collected in the shaking table test are the curves of acceleration with time at different measurement points. The data cannot express the dynamic damage mechanism of the slope under the action of seismic waves and its excellent periodic changes (law). Therefore, this section introduces the response spectrum analysis method often used in seismic wave processing. Through the shape of the acceleration response spectrum, the dynamic response characteristics of the slope can further be analyzed, which can provide an important reference for the design of slope management (value).

To study the variation law of the acceleration response spectrum of the slope supported by BFRP and steel anchors along the elevation, in this section, the input wave peak value is selected as a low earthquake $(0.15 \mathrm{~g})$, medium earthquake $(0.4 \mathrm{~g})$, or strong earthquake $(1.4 \mathrm{~g})$. The acceleration measurement points at the left and right of the two slopes in section II under the action of earthquake $(1.4 \mathrm{~g})$ are considered as the research objects. Their numbers are R5 (L5), R6 (L6), and R7 (L7) respectively, and each measurement point is away from the bottom of the slope. The vertical distances are $0.85 \mathrm{~m}, 1.15 \mathrm{~m}$, and $1.45 \mathrm{~m}$, respectively. Figures 16-18 show the acceleration response spectrum curves of each measurement point at the left and right of the two slopes in section II under the action of low, middle, and strong earthquake seismic waves, respectively. The engineering method is used to calculate the acceleration response spectrum. The commonly used damping ratio is $5 \%$, and the response spectrum curve is smoothed by the 25-point adjacent average method in the Origin software, which aims to clearly express the excellent period of the acceleration response spectrum.

In Figures 16-18, the trend of acceleration response spectrum at each measurement point of the slope supported by BFRP and steel anchors is basically the same, with obvious peak characteristics. In the short period ( $T=0.02 \sim 0.22 \mathrm{~s})$, the response spectrum distribution curve of each measuring point has obvious amplification effect along the elevation, while in the remaining long period (low frequency part), the amplification effect of the response spectrum curve of each measuring point along the elevation is not obvious. In addition, with the increase of the predominant period, the amplitude of the response spectrum decreases, and the amplitude of the acceleration response spectrum is basically 0 when the predominant period is $2 \mathrm{~s}$.

From the perspective of seismic wave energy transfer, the higher the strength and rigidity of the rock and the soil, the more conducive it is for the transfer of energy, and the more obvious is the acceleration amplification effect along the vertical, horizontal, and open surfaces of the slope. It shows that the slope near the monitoring section has better integrity; therefore, the slope acceleration response is closely related to the local damage mode of the slope rock and soil. To more clearly show the difference of the slope strengthened by BFRP and steel anchor, the acceleration response spectrum amplitude and predominant period of each measuring point in Figures 16-18 are extracted, as shown in Table 6.

It can be obtained from Table 6 that the response spectrum amplitudes of L5 and L6 in the middle of the left slope reinforced with steel anchors are close, while the response spectrum amplitudes of L7 in the upper slope and the other two measurement points in the middle slope are relatively different. Taking the $1.4 \mathrm{~g}$ seismic wave loading condition as an example, the acceleration response spectrum amplitude of L6 is $30.35 \mathrm{~m} / \mathrm{s}^{2}$, and that of L7 is $38.62 \mathrm{~m} / \mathrm{s}^{2}$, which is $27.1 \%$ higher than that of L6, indicating that the accumulated damage may occur in the soil near L7, which 


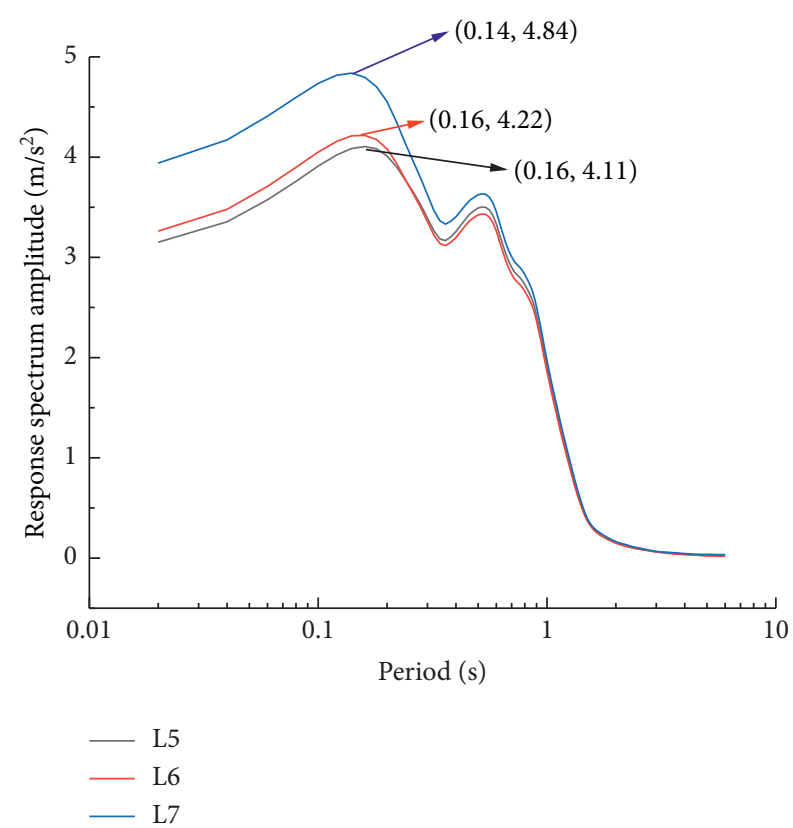

(a)

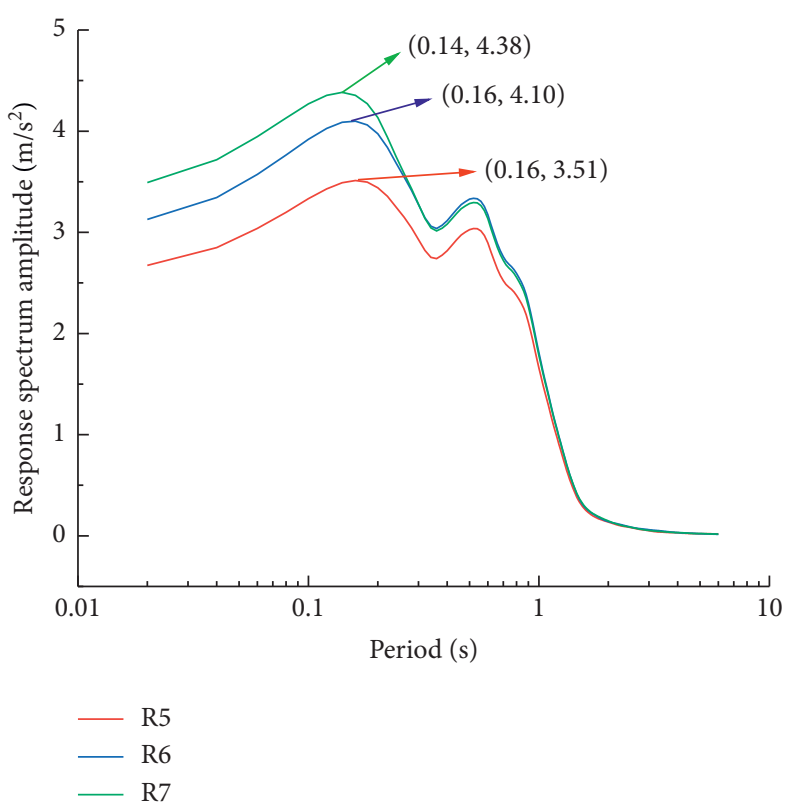

(b)

Figure 16: Acceleration response spectra of left and right slopes under a low earthquake $(0.15 \mathrm{~g})$. (a) The left-side slope. (b) The right-side slope.

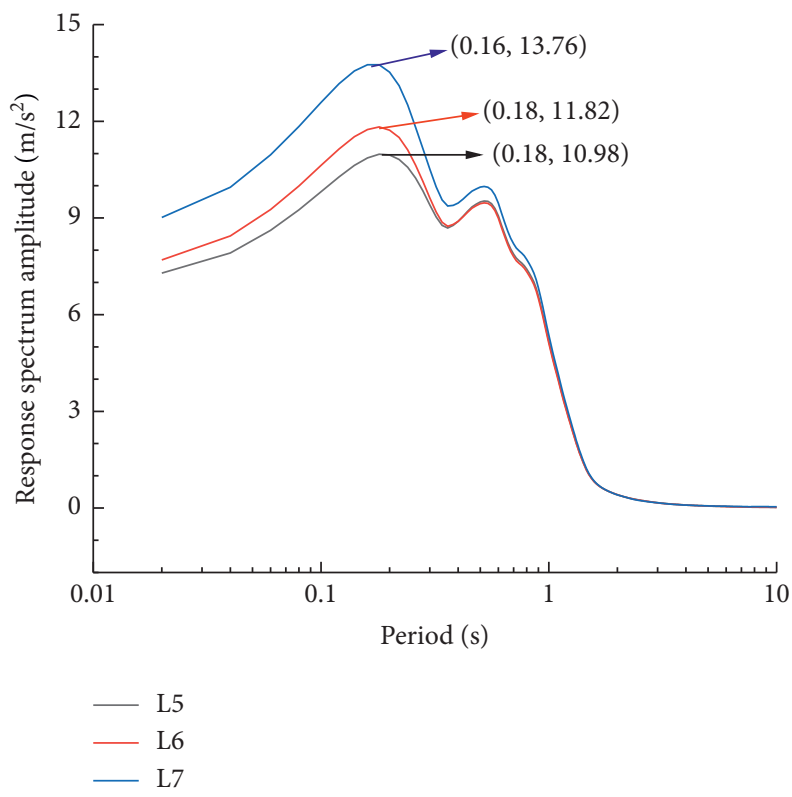

(a)

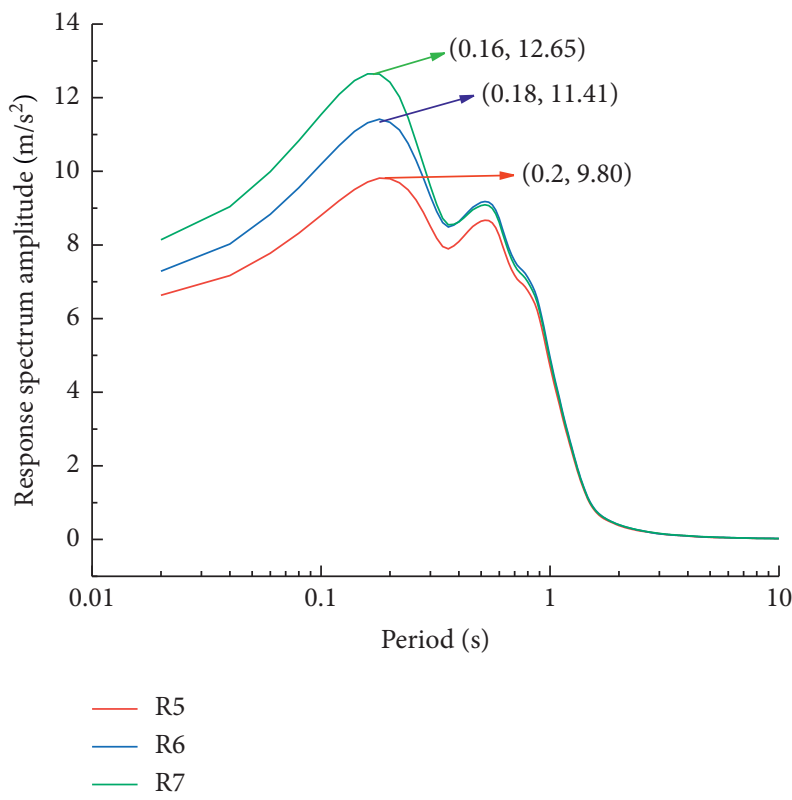

(b)

Figure 17: Acceleration response spectra of left and right slopes under a moderate earthquake (0.4 g). (a) The left-side slope. (b) The rightside slope.

leads to the difference. However, the response spectrum amplitudes of R7 in the upper slope and R5 and R6 in the middle of the right slope were reinforced with BFRT anchors, and there is no obvious zoning feature along the elevation. The results show that compared with the slope supported by steel anchors, BFRP anchors can improve the overall stability of the slope, especially limit the dynamic response of the middle and lower part of the slope. Although the model is damaged under the action of $1.4 \mathrm{~g}$ seismic wave, the BFRP anchor can still exert the flexibility 


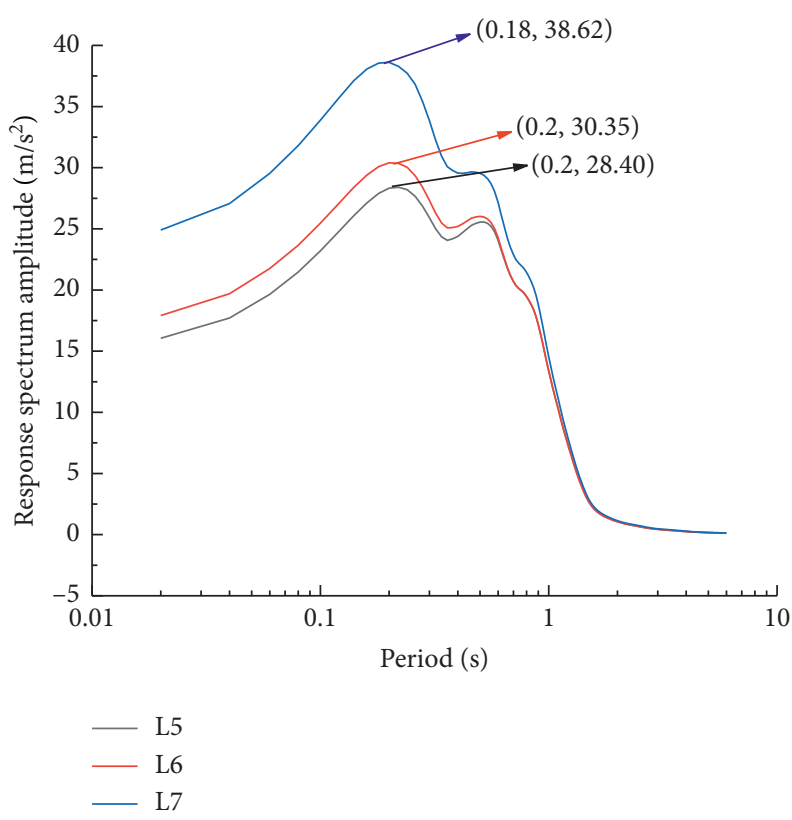

(a)

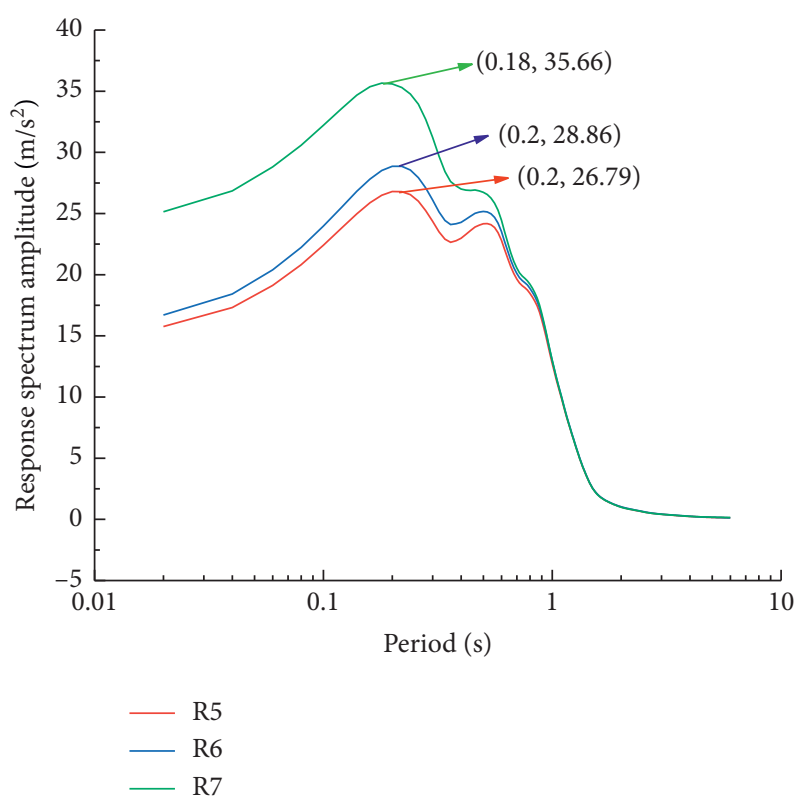

(b)

Figure 18: Acceleration response spectra of left and right slopes under a strong earthquake (1.4 g). (a) The left-side slope. (b) The right-side slope.

and ductility of its material, and effectively delay the failure time of the slope.

Furthermore, under the same working condition of loading seismic waves, the amplitude of the acceleration response spectrum of the right slope reinforced by BFRP anchor is smaller than that of the corresponding measurement point of the left slope reinforced by steel anchor, indicating that the dynamic response of the left slope is more severe under the action of the seismic wave. Taking the response of $\mathrm{L} 7$ and $\mathrm{R} 7$ under $1.4 \mathrm{~g}$ seismic wave loading condition as an example, the acceleration response spectrum amplitude of R7 is $35.66 \mathrm{~m} / \mathrm{s}^{2}$, and that of L7 is $38.62 \mathrm{~m} / \mathrm{s}^{2}$, which is 1.08 times of R7. This is because the flexible effect of BFRP anchor itself makes it play a certain role in energy dissipation of the seismic wave, which effectively reduces the impact of the seismic wave on the slope itself, and leads to the phenomenon of smaller amplitude of acceleration response spectrum in the right slope. In addition, with the increase of the peak value of the input wave, the predominant frequency of the left and right slopes decreases (the predominant period increases), which indicates that the nonlinear characteristics of the slope become more obvious. The soil has a filtering effect on the high-frequency seismic wave and an amplifying effect on the low-frequency seismic wave.

4.2. Analysis of the Change Law of the Displacement Spectrum. The seismic response spectrum mainly reflects the impact of earthquakes on the structure and can characterize the natural frequency (period) of the structure, which is widely used in evaluating the dynamic response of the structure. It has been reported that soil slope or rock slope as a structure will change its natural frequency (period) when a large local deformation or failure occurs. Therefore, in this section, the acceleration response measured at the measuring points R5 (L5), R6 (L6), and R7 (L7) in the left and right slopes are selected to calculate the respective displacement spectra $\left(S_{d}\right)$ of the two slopes. Figure 19 shows the displacement spectrum distribution of the left and right slopes under the action of low earthquakes $(0.15 \mathrm{~g})$, moderate earthquakes $(0.4 \mathrm{~g})$, and strong earthquakes (1.4 g).

In Figure 19, when the peak value of the input wave increases, the values of the displacement spectra in the two left and right slopes also increase. In addition, under the three operating conditions, the characteristic period corresponding to the maximum value of the displacement spectrum is $0.8 \mathrm{~s}$, indicating that the seismic wave at $1.25 \mathrm{~Hz}$ has the greatest influence on the deformation of the slope. When the characteristic period is greater than $1.5 \mathrm{~s}$, that is, the seismic wave frequency is less than $0.67 \mathrm{~Hz}$ and the characteristic period is less than $0.4 \mathrm{~s}$, that is, the seismic wave frequency is greater than $2.5 \mathrm{~Hz}$, the displacement spectra of the left and right slopes are small.

In Figure 19(a), under the action of low earthquakes, the displacement spectrum amplitudes of the two left and right slopes are less than $5.3 \mathrm{~cm}$. As the height of the arrangement along the measuring point increases, the displacement spectrum also increases, and the displacement spectrum values of the measuring points L7 and R7 at the location are the largest, respectively, $5.25 \mathrm{~cm}$ and $4.71 \mathrm{~cm}$. Moreover, the displacement spectrum value of each measuring point in the left slope is greater than that of the corresponding measuring point of the right slope. In the remaining two working conditions, the displacement spectrum also shows the same distribution law. In Figure 19(c), under the action of strong 
TABLE 6: Acceleration response spectrum amplitude and predominant period under various working conditions.

\begin{tabular}{lccc}
\hline Input peak & Measuring point & Amplitude $\left(\mathrm{m} / \mathrm{s}^{2}\right)$ & Predominant period (s) \\
\hline & L5 & 4.11 & 0.16 \\
& R5 & 3.51 & 0.16 \\
Low shock $(0.15 \mathrm{~g})$ & L6 & 4.22 & 0.16 \\
& R6 & 4.10 & 0.16 \\
& L7 & 4.84 & 0.14 \\
& R7 & 4.38 & 0.14 \\
\hline & L5 & 10.98 & 0.18 \\
Middle shock $(0.4 \mathrm{~g})$ & R5 & 9.80 & 0.20 \\
& L6 & 11.82 & 0.18 \\
& L7 & 11.41 & 0.18 \\
& R7 & 13.76 & 0.16 \\
Strong shock $(1.4 \mathrm{~g})$ & L5 & 12.65 & 0.16 \\
& R5 & 28.40 & 0.20 \\
& L6 & 26.79 & 0.20 \\
& R6 & 30.35 & 0.20 \\
& L7 & 28.86 & 0.20 \\
& R7 & 38.62 & 0.18 \\
\end{tabular}

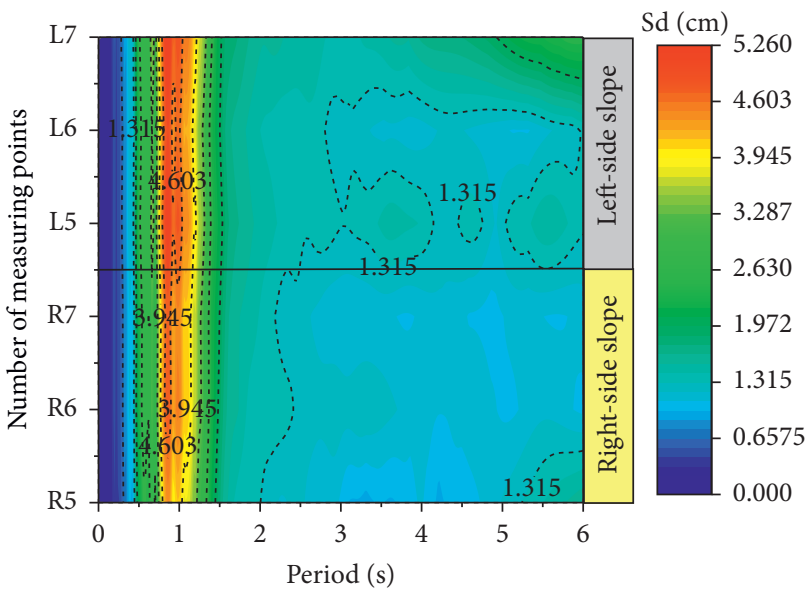

(a)

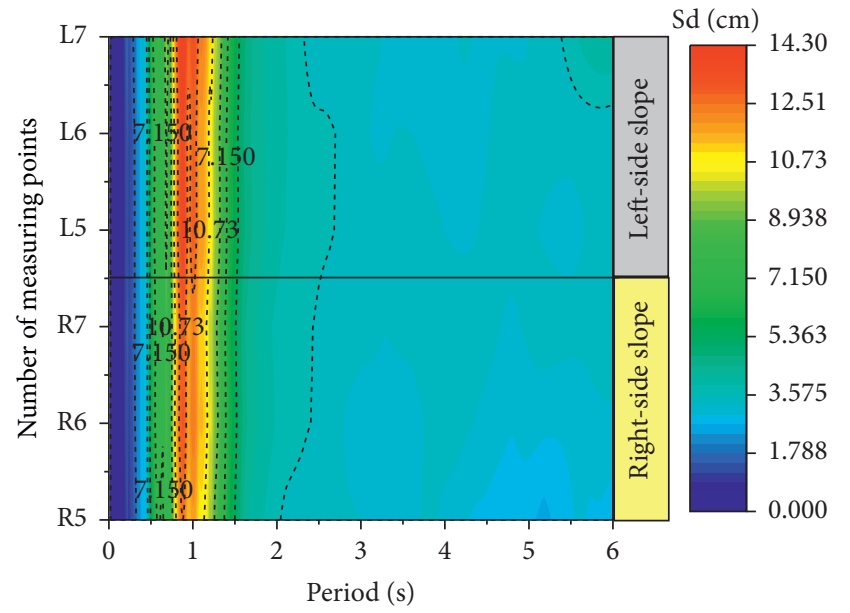

(b)

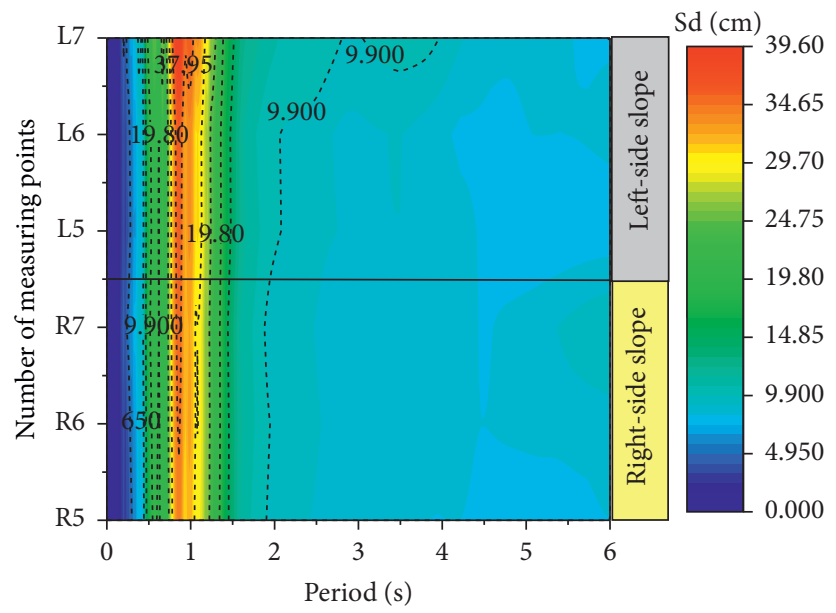

(c)

Figure 19: Displacement spectrum of the slope body under the action of low, middle, and strong earthquakes. (a) Displacement spectrum under a low earthquake $(0.15 \mathrm{~g})$. (b) Displacement spectrum under a moderate earthquake $(0.4 \mathrm{~g})$. (c) Displacement spectrum under a strong earthquake $(1.4 \mathrm{~g})$. 


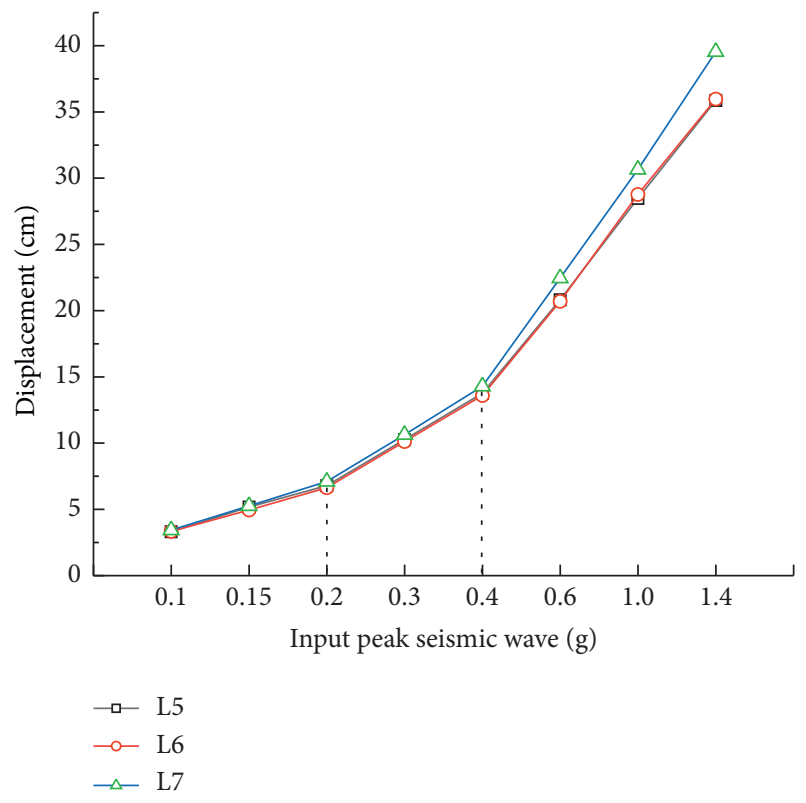

(a)

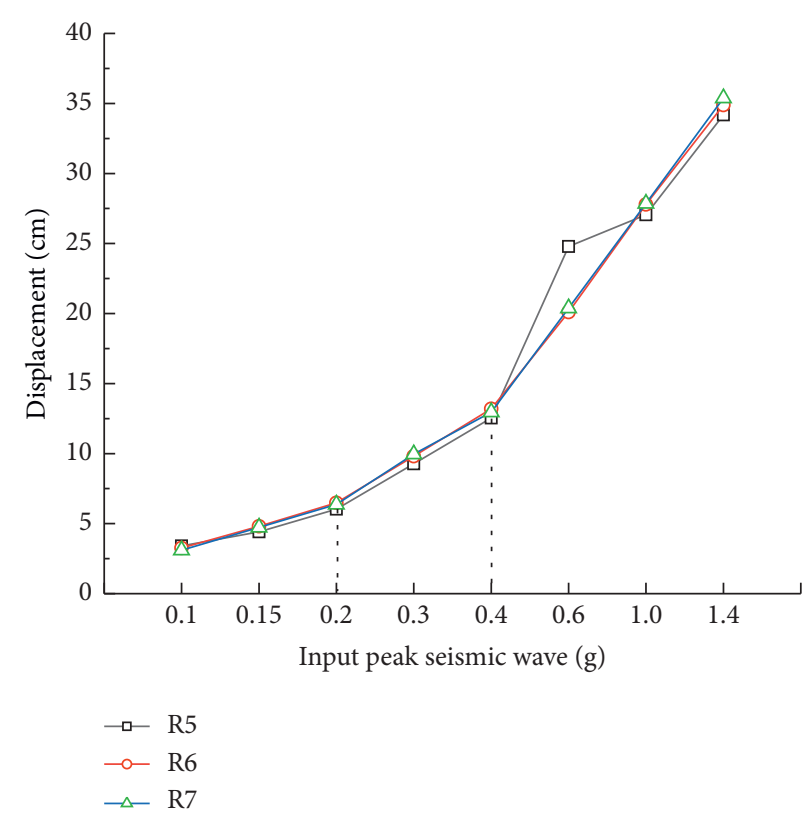

(b)

Figure 20: Displacement curve of the slope body. (a) The left-side slope. (b) The right-side slope.

earthquakes, both slopes are damaged. The maximum displacement spectrum of the left slope is at the measuring point of L7, and its value is $39.5 \mathrm{~cm}$, while that of the right is at R7 and its value is $34.3 \mathrm{~cm}$. The results indicate that when the BFRP anchor is used in slope supporting engineering, it can enhance the deformation limit of the slope body, which is beneficial to improve the seismic performance of the slope body.

The displacements of the left and right slopes under various conditions are shown in Figure 20. For the left and right slopes, the slope displacement also increases with the increase of the input peak acceleration. When the peak value of the input wave is $0.2 \mathrm{~g}$ and $0.4 \mathrm{~g}$, the displacement of the left and right slopes, respectively, has a sudden change. The reason is that, the slope changes from the elastic stage to the plastic stage under the action of $0.2 \mathrm{~g}$ seismic wave, and the sliding surface of the slope is formed under the action of the $0.4 \mathrm{~g}$ seismic wave. We were convinced that as the cumulative damage inside the slope increased, cracks gradually increased (consumption of seismic energy) and the filtering effect became more and more intensified. In the plastic enhancement stage, the amplitude of the dynamic stress intensity factor of the rock mass increased to its fracture toughness, resulting in a sharp decrease in the number of microscopic cracks and a significant increase in the damage rate. The accelerated expansion into macroscopic cracks and the slope displacement increases gradually. Furthermore, the integrity of the slope rock mass is seriously damaged and its bearing capacity is significantly weakened (critical instability stage), and further penetration of macro cracks will promote the failure of the model.

Comparing Figure 20(a) and 20(b), it can be found that the displacement of the slope reinforced by steel anchor is greater than that reinforced by the BFRP anchor, except for the R5 under the seismic action of the $0.6 \mathrm{~g}$. Taking the $1.4 \mathrm{~g}$ extreme seismic wave loading condition as an example, the displacement of L5, L6, and L7 is $35.86,35.97$, and $39.55 \mathrm{~cm}$, respectively, while the displacement of R5, R6, and R7 is $34.19,34.88$, and $35.38 \mathrm{~cm}$, respectively, which is $95.3 \%$, $96.9 \%$, and $89.4 \%$ of L5, L6, and L7, respectively. In addition, the displacement change of the upper measuring point L7 on the left slope is more obvious than that of R7 of the right slope. When the slope is destroyed under the action of an earthquake, BFRP anchors as the flexible structure can allow the slope to appear as proper displacement, and the flexibility and ductility of the anchor can coordinate the deformation of the slope. It shows that the seismic effect of BFRP anchor in slope support is better than that of steel anchor, and it can limit the displacement of the slope better.

Furthermore, the macroscopic test phenomenon also confirmed from the other side that the deformation and damage caused by the BFRP anchored slope are less than that of the steel anchored slope. These research results show that when the BFRP anchor is used as a flexible material in slope support engineering, it can make full use of its advantages, such as higher tensile strength, lower elastic modulus, and better ground stress transfer characteristics, relative to steel anchor. It can effectively adapt to the deformation of the slope, reduce the seismic damage caused by the different dynamic responses of the slope at different height positions, and has good antiseismic performance.

\section{Conclusion}

To study the dynamic response of the slope reinforced by BFRP anchors under earthquake and verify the possibility and superiority of BFRP anchors instead of steel anchors in a high-intensity earthquake area, a large-scale shaking table 
test of two kinds of anchors for slope reinforcement was carried out. The acceleration dynamic response and displacement dynamic response of slopes with BFRP and steel anchors are compared, and the conclusions are as follows:

(1) The slope model reinforced by BFRP and steel anchors showed a significant deformation stage during the seismic wave loading process, that is, elastic, plastic (potential sliding surface and plastic strengthening), and failure stages, respectively. The slope model was in the elastic stage before the $0.2 \mathrm{~g}$ seismic wave, gradually entered the plastic stage after the $0.4 \mathrm{~g}$ seismic wave, and was basically destroyed under the $1.4 \mathrm{~g}$ seismic wave.

(2) The peak acceleration and displacement of the slope reinforced by steel anchors are greater than those of the slope reinforced by BFRP anchors under the same working conditions of seismic waves. Furthermore, the BFRP materials can absorb and reflect part of the energy, and the flexibility effect of BFRP anchors has an obvious energy dissipation effect and a certain attenuation effect on the seismic wave.

(3) With the increase of the amplitude of the loading seismic wave, the predominant frequency of the slope model decreases, which indicate that the nonlinear characteristics of the slope has become more obvious. The soil has a filtering effect on the high-frequency seismic wave and an amplification effect on the low-frequency seismic wave.

(4) When the BFRP anchors as a flexible structure to reinforce the slope, it can allow proper displacement of the slope, which can play a role in coordinating the deformation of the slope compared to steel anchors. Furthermore, the BFRP anchors can improve the overall stability of the slope. It can especially restrain the dynamic response of the middle and lower parts of the slopes.

\section{Data Availability}

The data used to support the findings of this study are available from the corresponding author upon request.

\section{Disclosure}

Zhixin $\mathrm{Wu}$ and Hao Lei are the co-first authors.

\section{Conflicts of Interest}

The authors declare that there are no conflicts of interest.

\section{Authors' Contributions}

Zhixin $\mathrm{Wu}$ and Hao Lei contributed equally to this work.

\section{Acknowledgments}

This research was supported by the National Key R \& D Program of China (2018YFC1504901), the Natural Science Foundation of Gansu Province (145RJZA068), and the
Yunnan Provincial Department of Transportation (Yunjiao Science and Education (2017) 37-1). The authors are grateful for the support from the Key Laboratory of Loess Earthquake Engineering, CEA.

\section{References}

[1] Y. Jin, M. He, S. Wang, and C. Liu, "Study on the anchoring mechanism of pre-stressed anchor cable with dispersive pressure suitable for soft: rock slope reinforcing," China Civil Engineering Journal, vol. 39, no. 4, pp. 63-67, 2006.

[2] H. Ye, Y. Zheng, A. Li, and X. Du, "Shaking table test studies of prestressed anchor cable of slope under earthquake," Chinese Journal of Rock Mechanics and Engineering, vol. 31, no. S1, pp. 2847-2854, 2012.

[3] M. Wang, H. Li, Y. Liu, W. Zhang, and X.-C. Huang, "Reinforcement mechanism of bedding rock slopes with prestressed anchor cable subjected to seismic loads," Rock and Soil Mechanics, vol. 34, no. 12, pp. 3555-3560, 2013.

[4] D. Zheng, L. Liang, and N. Ju, "Seismic damage of prestressed anchor cables under low frequency cycling loads," Chinese Journal of Rock Mechanics and Engineering, vol. 34, no. 7, pp. 1353-1360, 2015.

[5] Z. Wu, H. Wu, X. Xie et al., "Shaking table test of traditional anchorage and BFRP anchorage in high slope protection," The Chinese Journal of Geological Hazard and Control, vol. 30, no. 6, pp. 94-104, 2019.

[6] L. Cheng, "Present status and development of ground anchorages," China Civil Engineering Journal, vol. 34, no. 3, pp. 7-12, 2001.

[7] M. T. Kim and K. Y. Rhee, "Flexural behavior of carbon nanotube-modified epoxy/basalt composites," Carbon Letters, vol. 12, no. 3, pp. 177-179, 2011.

[8] M. Pearson, T. Donchev, and J. Salazar, "Long-term behaviour of prestressed basalt fibre reinforced polymer bars," Procedia Engineering, vol. 54, no. 54, pp. 261-269, 2013.

[9] Y. Chen, F. Davalos Julio, I. Ray, and H. Y. Kim, "Accelerated aging tests for evaluations of durability performance of FRP reinforcing bars for concrete structures," Composite Structures, vol. 78, no. 1, pp. 101-111, 2007.

[10] J. Huang and R. Aboutaha, "Environmental reduction factors for GFRP bars used as concrete reinforcement: new scientific approach," Journal of Composites for Construction, vol. 14, no. 5, pp. 479-486, 2010.

[11] J. F. Davalos, Y. Chen, and I. Ray, "Long-term durability prediction models for GFRP bars in concrete environment," Journal of Composite Materials, vol. 46, no. 16, pp. 1899-1914, 2012.

[12] M. Robert, P. Wang, P. Cousin, and B. Benmokrane, "Temperature as an accelerating factor for long-term durability testing of FRPs: should there be any limitations," Journal of Composites for Construction, vol. 14, no. 4, pp. 361-367, 2010.

[13] W. Bin, C. Hailin, and S. Shenhua, "Retracted: environmental resistance and mechanical performance of basalt and glass fibers," Materials Science and Engineering, vol. 44, no. 3, 2010.

[14] C. Scheffler, T. Förster, E. Mäder, G. Heinrich, S. Hempel, and $\mathrm{V}$. Mechtcherine, "Aging of alkali-resistant glass and basalt fibers in alkaline solutions: evaluation of the failure stress by Weibull distribution function," Journal of Non-Crystalline Solids, vol. 355, no. 52-54, pp. 2588-2595, 2009.

[15] A. El Refai, "Durability and fatigue of basalt fiber-reinforced polymer bars gripped with steel wedge anchors," Journal of Composites for Construction, vol. 17, no. 6, 2013. 
[16] A. Altalmas, A. El Refai, and F. Abeda, "Bond degradation of basalt fiber-reinforced polymer (BFRP) bars exposed to accelerated aging conditions," Construction and Building Materials, vol. 81, pp. 162-171, 2015.

[17] Z. Lu and G. Xian, "Combined effects of sustained tensile loading and elevated temperatures on the mechanical properties of pultruded BFRP plates," Construction and Building Materials, vol. 150, pp. 310-320, 2017.

[18] M. Urbanski, A. Lapko, and A. Garbacz, "Investigation on concrete beams reinforced with basalt rebars as an effective alternative of conventional R/C structures," Procedia Engineering, vol. 57, pp. 1183-1191, 2013.

[19] H. Zhang, S. T. Smith, R. J. Gravina, and Z. Wang, "Modelling of FRP-concrete bonded interfaces containing FRP anchors," Construction and Building Materials, vol. 139, pp. 394-402, 2017.

[20] H. Zhang and S. T. Smith, "Influence of plate length and anchor position on FRP-to-concrete joints anchored with FRP anchors," Composite Structures, vol. 159, pp. 615-624, 2017.

[21] F. Jun, Y. Wang, Y. Zhang et al., "Field test and research on the anchoring performance of basalt fiber and reinforced anchor," Rock and Soil Mechanics, vol. 40, no. 11, pp. 4185-4193, 2019.

[22] C. Yuan, W. Chen, T. M. Pham, H. Hao, L. Chen, and M. Zhang, "New epoxy anchor for better bonding between FRP sheets and concrete," Construction and Building Materials, vol. 248, Article ID 118628, 2020.

[23] H. Liu, J. Yang, and X. Wang, "Bond behavior between BFRP bar and recycled aggregate concrete reinforced with basalt fiber," Construction and Building Materials, vol. 135, no. 15, pp. $477-483,2017$.

[24] F. Nerilli and G. Vairob, "Experimental investigation on the debonding failure mode of basalt-based FRP sheets from concrete," Composites Part B: Engineering, vol. 153, pp. 205216, 2018.

[25] Z. Lei, K. Jing-wen, Z. Wen, and X. Qiang, "Experimental study on determining design parameters of non-prestressed BFRP anchor for supporting soil slope," Journal of Highway and Transportation Research and Development, vol. 11, no. 4, pp. 32-42, 2017.

[26] J. X. Liu, "Comparative study on expansive soil steep slope FRP materials bolt support," Applied Mechanics and Materials, vol. 454, pp. 250-254, 2014.

[27] J. H. Jin, H. T. Lim, T. Bibek et al., "Slope behavior analysis using the measurement of GFRP underground displacement," Journal of Korean Geosynthetics Society, vol. 17, 2018.

[28] S. Ho, Lee, Y. Cheol et al., "A study appropriate on the standard of FRP reinforcements method for soil slope according to a change of slope height and shear strength," Proceedings of Korean Geo Environmental Society, vol. 9, pp. 131-142, 2007.

[29] S. Huang, Y. Lyu, and Y. Peng, "Application research of new cementitious composite materials in saline soil subgrade aseismic strengthening," Advances in Civil Engineering, vol. 2020, Article ID 7525692, 18 pages, 2020.

[30] S. Huang, M. Huang, and Y. Lyu, "An improved KNN-based slope stability prediction model," Advances in Civil Engineering, vol. 2020, Article ID 8894109, 16 pages, 2020.

[31] S. C. Kim and D. W. Lee, "Evaluation of the applicability of FRP grouted reinforcing method for rock slopes," Korean Journal of Agricultural Science, vol. 35, no. 2, pp. 213-223, 2008.

[32] Z. Wu, D. Zhang, S. Wang, C. Liang, and D. Zhao, "Dynamicresponse characteristics and deformation evolution of loess slopes under seismic loads," Engineering Geology, vol. 267, Article ID 105507, 2020.

[33] C. Guo-xing, Z.-H. Wang, X. Zuo, X.-L. Du, and X.-J. Han, "Development of laminar shear soil container for shaking table tests," Chinese Journal of Geotechnical Engineering, vol. 32, no. 1, pp. 89-97, 2010.

[34] N. Ma, H. Wu, H. Ma, X. Wu, and G. Wang, "Examining dynamic soil pressures and the effectiveness of different pile structures inside reinforced slopes using shaking table tests," Soil Dynamics and Earthquake Engineering, vol. 116, pp. 293-303, 2019.

[35] X. Ling, Q. Hu, J. Ou et al., "A scale modeling method of simulation explosion test of soil-structure impactive interaction due to exploding," Rock and Soil Mechanics, vol. 25, no. 8, pp. 1249-1253, 2004.

[36] Z. Wang, J. Zhang, Fuxiao et al., "Isolated similar design method for a scaled model test and its application to slopeanchor cable-lattice beam system," Rock and Soil Mechanics, vol. 37, no. 9, pp. 2617-2623, 2016.

[37] B. Louis, "The Pi theorem of dimensional analysis," Archive for Rational Mechanics \& Analysis, vol. 1, no. 1, pp. 35-45, 1957.

[38] S. Zhang, X.-J. Pei, S.-Y. Wang, and R.-Q. Huang, "Centrifuge model testing of loess landslides induced by excavation in northwest China," International Journal of Geomechanics, vol. 20, no. 14, 2020.

[39] S. Zhang, X. Pei, S. Wang, R. Huang, X. Zhang, and Z. Chang, "Centrifuge model testing of a loess landslide induced by rising groundwater in northwest China," Engineering Geology, vol. 259, Article ID 105170, 2019.

[40] A. Che, H. Yang, B. Wang, and X. Ge, "Wave propagations through jointed rock masses and their effects on the stability of slopes," Engineering Geology, vol. 201, pp. 45-56, 2016.

[41] Q. Da, Introduction to Spectral Analysis of Ground Motion, Earthquake Press, Beijing, China, 1980.

[42] H. Wu, Z. Wu, X. Xie et al., "Experimental study on large vibration table of soil slopemicropile composite structure," Rock and Soil Mechanics, vol. 40, no. 10, pp. 3844-3854, 2019.

[43] L. Nan, Y. Men, O. Gao et al., "Study on seismic dynamic response of micro pile group supporting landslide," Chinese Journal of Rock Mechanics and Engineering, vol. 37, no. 9, pp. 2144-2151, 2018.

[44] X. Chen, J. Shen, P. Wei et al., "Large scale shaking table test of seismic stability of Xiashu loess slopes (II) - analysis of test results," Journal of Disaster Prevention and Mitigation Engineering, vol. 30, no. 6, pp. 587-594, 2010. 